\title{
A New Type of Satellite Associated with Cassava Mosaic Begomoviruses
}

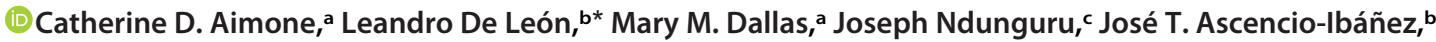 \\ Linda Hanley-Bowdoin ${ }^{a}$
}

aDepartment of Plant and Microbial Biology, North Carolina State University, Raleigh, North Carolina, USA

bDepartment of Molecular and Structural Biochemistry, North Carolina State University, Raleigh, North Carolina, USA

cTari Selian, Arusha, Tanzania

ABSTRACT Cassava mosaic disease (CMD), which is caused by single-stranded DNA begomoviruses, severely limits cassava production across Africa. A previous study showed that CMD symptom severity and viral DNA accumulation increase in cassava in the presence of a DNA sequence designated SEGS-2 (sequence enhancing geminivirus symptoms). We report here that when SEGS-2 is coinoculated with African cassava mosaic virus (ACMV) onto Arabidopsis thaliana, viral symptoms increase. Transgenic Arabidopsis with an integrated copy of SEGS-2 inoculated with ACMV also display increased symptom severity and viral DNA levels. Moreover, SEGS-2 enables Cabbage leaf curl virus (CaLCuV) to infect a geminivirus-resistant Arabidopsis thaliana accession. Although SEGS-2 is related to cassava genomic sequences, an earlier study showed that it occurs as episomes and is packaged into virions in CMD-infected cassava and viruliferous whiteflies. We identified SEGS-2 episomes in SEGS-2 transgenic Arabidopsis. The episomes occur as both double-stranded and single-stranded DNA, with the single-stranded form packaged into virions. In addition, SEGS-2 episomes replicate in tobacco protoplasts in the presence, but not the absence, of ACMV DNA-A. SEGS-2 episomes contain a SEGS-2 derived promoter and an open reading frame with the potential to encode a 75-amino acid protein. An ATG mutation at the beginning of the SEGS-2 coding region does not enhance ACMV infection in A. thaliana. Together, the results established that SEGS-2 is a new type of begomovirus satellite that enhances viral disease through the action of an SEGS-2-encoded protein that may also be encoded by the cassava genome.

IMPORTANCE Cassava is an important root crop in the developing world and a food and income crop for more than 300 million African farmers. Cassava is rising in global importance and trade as the demands for biofuels and commercial starch increase. More than half of the world's cassava is produced in Africa, where it is primarily grown by smallholder farmers, many of whom are from the poorest villages. Although cassava can grow under high temperature, drought, and poor soil conditions, its production is severely limited by viral diseases. Cassava mosaic disease (CMD) is one of the most important viral diseases of cassava and can cause up to $100 \%$ yield losses. We provide evidence that SEGS-2, which was originally isolated from cassava crops displaying severe and atypical CMD symptoms in Tanzanian fields, is a novel begomovirus satellite that can compromise the development of durable CMD resistance.

KEYWORDS Arabidopsis, begomovirus, cassava mosaic disease, SEGS

assava (Manihot esculenta Crantz), a major root crop in Africa, originated in South America and was introduced into Africa by Portuguese colonizers in the 16th century (1). Cassava grows in acidic soil and under drought and high temperature conditions, making it an important staple crop for many smallholder farmers $(1,2)$. Cassava
Citation Aimone CD, De León L, Dallas MM Ndunguru J, Ascencio-lbáñez JT, Hanley-Bowdoin L. 2021. A new type of satellite associated with cassava mosaic begomoviruses. J Virol 95:e00432-21. https:// doi.org/10.1128/JVI.00432-21.

Editor Anne E. Simon, University of Maryland College Park

Copyright $\odot 2021$ Aimone et al. This is an open-access article distributed under the terms of the Creative Commons Attribution 4.0 International license.

Address correspondence to Catherine D.

Aimone, cddoyle@ncsu.edu

* Present address: Leandro De León, Department of Biochemistry, Microbiology, Cell Biology and Genetics, Universidad de La Laguna, S/C de Tenerife, Spain.

Received 23 March 2021

Accepted 10 August 2021

Accepted manuscript posted online

18 August 2021

Published 13 October 2021 
mosaic disease (CMD) is one of the most devastating diseases of cassava (3). Losses due to CMD have an immediate impact on the food supply and threaten food security and the livelihoods of Africa's rapidly growing population (1, 2). CMD also causes serious problems for cassava production on the Indian subcontinent and increasingly in southeast Asia and China (4-6).

CMD is caused by a complex of at least 11 cassava mosaic begomoviruses (CMBs), of which nine occur in Africa and two are found on the Indian subcontinent (7). They include members of the species African cassava mosaic virus (ACMV), East African cassava mosaic virus (EACMV), East African cassava mosaic Cameroon virus (EACMCV), East African cassava mosaic Malawi virus (EACMMV), East African cassava mosaic Zanzibar virus (EACMZV), East African cassava mosaic Kenya virus (EACMKV), Cassava mosaic Madagascar virus (CMMGV), African cassava mosaic Burkina Faso virus (ACMBFV), Indian cassava mosaic virus (ICMV), South African cassava mosaic virus (SACMV), and Sri Lankan cassava mosaic virus (SLCMV) (7).

Begomoviruses constitute the largest genus of the Geminiviridae, a family of plant DNA viruses characterized by twin icosahedral particles (8). They have small, circular single-stranded DNA (ssDNA) genomes that also occur as double-stranded DNA (dsDNA) replication intermediates in infected plants $(9,10)$. Their genomes consist of either one or two DNA components ranging in size from 2.5 to $2.9 \mathrm{~kb}$ (11). CMBs have two genome components, designated DNA-A and DNA-B (12). The DNA-A component can replicate autonomously and produce virions in infected plants, while DNA-B is required for cell-to-cell and systemic movement (for a review, see reference 13). DNA-A encodes 5 to 6 proteins involved in replication, transcription, enscapsidation, and countering host defenses, while DNA-B encodes two proteins necessary for movement (13). Like all begomoviruses, CMBs are transmitted by whiteflies (Bemisia tabaci Genn) (14). They are also spread by vegetative propagation of stem cuttings from CMDinfected cassava (15).

CMBs evolve rapidly via a combination of nucleotide substitution, recombination, and genome reassortment (16-18), which can result in the emergence of new and more virulent viruses $(19,20)$. CMBs often occur in mixed infections, leading to synergism between the different viruses and increased symptom severity $(17,21)$. In the 1990s and 2000s, synergism of a CMB recombinant between ACMV and EACMV contributed to a severe pandemic that spread from Uganda to other sub-Saharan countries and devastated cassava production (22). In response to the pandemic, many African farmers adopted cassava cultivars with the CMD2 locus, which confers resistance to $\mathrm{CMBs}(23,24)$.

Many begomoviruses are associated with satellite DNAs that are packaged into virions and can increase virulence and alter host range (25-27). To date, 3 types of DNA satellites have been described, including alphasatellites, betasatellites, and deltasatellites (28-30). Alphasatellites and betasatellites are approximately 1,300 to 1,400 nucleotides (nt) in size and contain one major open reading frame (ORF), a hairpin structure, and an adenine-rich region (28-30). Deltasatellites are related to betasatellites but range from ca. $540 \mathrm{nt}$ to750 nt in size (30). Betasatellites rely on the Rep protein of their helper virus for replication, whereas alphasatellites encode their own Rep protein and replicate autonomously $(27,31)$.

Betasatellites encode a single protein, $\beta C 1$, that enhances geminivirus symptoms by suppressing posttranscriptional gene silencing (PTGS) and transcriptional silencing (TGS) $(32,33)$. Some alphasatellites display silencing suppression activity and increased symptom severity (28), while others are associated with attenuation of symptoms (34). A New World alphasatellite associated with increased symptom severity of the begomovirus Euphorbia yellow mosaic virus has been documented in Euphorbia heterophylla, which belongs to the same family as cassava (35). Deltasatellites are noncoding DNAs that can reduce the titer of associated begomoviruses (30). An alphasatellite has been found in CMB-infected cassava in Madagascar off the coast of East Africa (36), but there are no reports of satellites associated with CMD on the African continent. However, coinoculation studies in Nicotiana benthamiana showed that some CMBs can interact 
with heterologous beta and alpha satellites to impact symptoms and viral DNA accumulation (37).

Two novel DNAs, designated SEGS-1 (DNA-II; GenBank accession no. AY836366) and SEGS-2 (DNA-III; AY836367; for sequences enhancing geminivirus symptoms), were isolated from cassava plants showing severe, atypical CMD symptoms in fields near the Tanzanian coast (38). SEGS-1 and SEGS-2 both contain regions with high GC content but are distinct DNAs that only share $23 \%$ sequence identity. Sequences related to both SEGS occur in the cassava genome, with the most closely related copies displaying $99 \%$ and 84 to $87 \%$ identity to the cloned SEGS-1 and SEGS-2 sequences, respectively. Controlled inoculation experiments showed that both SEGS-1 and SEGS-2 enhance CMD symptoms in cassava (38).

Both SEGS-1 and SEGS-2 occur as circular episomes in infected but not healthy cassava leaves. SEGS-2 episomes are also found in DNA from viruliferous whiteflies and in virions from cassava and whiteflies, indicating that SEGS-2 is packaged and acquired by whiteflies (38). The SEGS-2 episome includes a 52-bp sequence that does not match the cassava genome but contains a 26-bp motif related to alphasatellite sequences. The alphasatellite motif may reflect a recombination event between the cassava genome and an alphasatellite (38).

The presence of sequences related to SEGS-2 in the cassava genome has complicated functional studies of SEGS-2. To overcome this constraint, we examined SEGS-2 during CMB infection of Arabidopsis thaliana plants and Nicotiana tabacum suspension cells. These studies provide evidence that SEGS-2 is a new type of begomovirus satellite associated with disease enhancement.

\section{RESULTS}

SEGS-2 enhances ACMV symptoms in Arabidopsis. To establish Arabidopsis thaliana as a model system for studying SEGS-2, we first asked if ACMV can infect Arabidopsis thaliana. A previous report showed that the related CMB, SACMV, can infect the $A$. thaliana Col-0 accession (39), but we were unable to infect Col-0 plants with ACMV. Hence, we determined if the hypersusceptible $A$. thaliana accession, Sei-0 (40), can be infected with ACMV when cobombarded with partial tandem dimers of DNA-A and DNA-B (Fig. $1 \mathrm{~A}$ and B). As shown in Fig. 1B, we observed ACMV infection in Sei-0. However, the timing of symptom appearance varied between experiments, most likely because ACMV is not well adapted to $A$. thaliana as a host. For this reason, we assayed 9 plants/treatment and only compared treatments within an experiment in which the plants were grown and inoculated together. Conclusions are based on three replicates for each experiment.

To examine the impact of SEGS-2 on ACMV infection, we generated a set of SEGS-2 constructs (Fig. 1A) for cobombardment with the infectious ACMV clones. The constructs were derived from the SEGS-2 clone originally amplified from CMB-infected cassava using an alphasatellite universal primer (38). S2-1.5a and S2-1.5b are partial tandem dimers with different halves of SEGS-2 duplicated. The design of the SEGS-2 1.5-mer clones was based on begomovirus infectious clones. We also generated an SEGS-2 monomer clone (S2-1.0) that does not contain primer sequences that were introduced during construction of the original SEGS-2 clone.

Sei-0 plants were bombarded with ACMV DNA-A and DNA-B infectious clones alone or in the presence of an SEGS-2 clone. Plants inoculated only with ACMV showed very mild symptoms on rosette and cauline leaves at 24 and 31 days postinfection (dpi), respectively (Fig. 1B). In contrast, plants cobombarded with ACMV and SEGS-2 displayed strong leaf curling and stunting at the same times (Fig. 1B). Severe symptoms were also apparent at $25 \mathrm{dpi}$ on plants (Fig. 1C) coinoculated with ACMV and one of the SEGS-2 clones in Fig. 1A (S2-1.5a, S2-1.5b, or S2-1.0). Symptoms were monitored over time (12 to $35 \mathrm{dpi}$ ) using a scale of 1 (none) to 5 (strong chlorosis, stunting, and leaf deformation) (Fig. 1D and E). The average symptom scores for plants inoculated with ACMV alone were consistently lower than those for plants inoculated with ACMV 
A

\begin{tabular}{|c|c|c|}
\hline S2-1.0 & GC-Rich & \\
\hline s2-1.5a & GC-Rich & GC-Rich \\
\hline
\end{tabular}
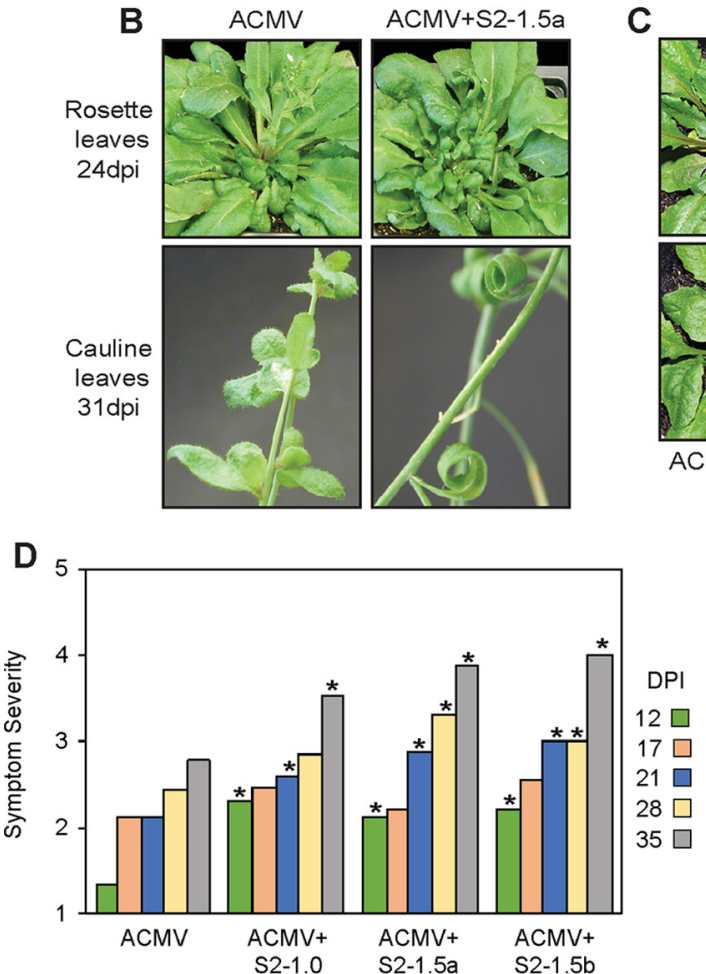

C

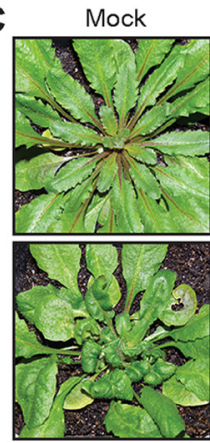

$\mathrm{ACMV}+\mathrm{S} 2-1.5 \mathrm{a}$
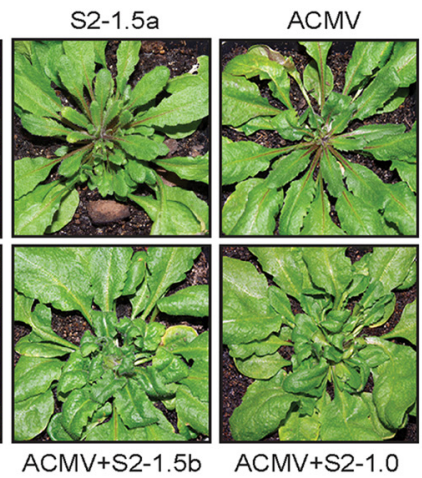

ACMV+S2-1.0

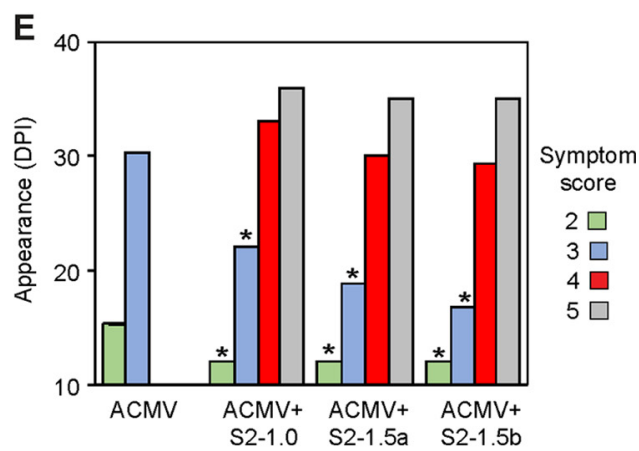

FIG 1 SEGS-2 enhances CMB infection in Arabidopsis thaliana. (A) Diagram of SEGS-2 clones used for infection studies. S21.0 contains a single copy of SEGS-2. S2-1.5a and S2-1.5b are partial tandem dimers with duplicated regions shown in gray. The GC-rich region is indicated in each construct. (B) Rosette and cauline leaves of wild-type Arabidopsis Sei-0 plants inoculated with ACMV DNA-A + DNA-B alone (left) or in combination with S2-1.5a (right). The rosette and cauline images are at 24 and $31 \mathrm{dpi}$, respectively. (C) Arabidopsis Sei-0 inoculated with ACMV alone or in combination with S2-1.0, S2$1.5 \mathrm{a}$, or S2-1.5b at $25 \mathrm{dpi}$. (D) Symptom score on a scale of 1 (none) to 5 (strong chlorosis, stunting, and leaf deformation) for wild-type Sei-0 inoculated with ACMV alone or in combination with S2-1.0, S2-1.5a, or S2-1.5b from 12 to 35 dpi. (E) Average day postinfection of symptom appearance for wild-type Sei-0 inoculated with ACMV alone or in combination with S2-1.0, S2-1.5a, or S2-1.5b.

and SEGS-2 (Fig. 1D). The differences were statistically significant at 12, 21, 28, and $35 \mathrm{dpi}$ in comparisons between ACMV alone and ACMV+SEGS-2 plants. The average time of symptom appearance was also later for plants inoculated with ACMV alone than for plants inoculated with ACMV+SEGS-2 (Fig. 1E). The delay was significant for symptom scores 2 and 3. Strikingly, symptom scores 4 and 5 were only observed in plants inoculated with ACMV+SEGS-2. The configuration of the SEGS-2 clones had minor effects on symptoms, with S2-1.0 showing milder symptoms and a delay in appearance relative to S2-1.5a and S2-1.5b (Fig. 1D and E). Together, these results showed that like cassava (38), SEGS-2 enhances ACMV infection in Sei-0 plants, establishing that $A$. thaliana can be used as a model system to study SEGS-2.

A SEGS-2 transgene enhances ACMV symptoms. The cassava genome contains sequences related to SEGS-2, prompting us to ask if SEGS-2 can enhance ACMV infection when it is integrated into the $A$. thaliana genome. We produced transgenic Sei-0 lines with the SEGS-2 monomer sequence cloned into the Ti plasmid DNA vector in both orientations. The transgenic plants were readily recovered and appeared phenotypically normal, indicating that the SEGS-2 sequence by itself does not have a visible impact on $A$. thaliana plants.

SEGS-2 transgenic plants were inoculated with ACMV alone, and symptoms and viral DNA accumulation were examined. Transgenic plants carrying SEGS-2 in either orientation 
(T-S2-1.0F or T-S2-1.0R) displayed strong symptoms at $28 \mathrm{dpi}$, while wild-type (WT) Sei-0 plants only showed mild symptoms (Fig. 2A). The average symptom scores of the transgenic lines were significantly higher than those of wild-type plants at 14, 21, and $28 \mathrm{dpi}$ but not at $35 \mathrm{dpi}$ (Fig. 2B). Cobombardment of the transgenic plants with S2-1.5b plasmid DNA plus ACMV did not increase symptom severity (Fig. 2C), indicating that the SEGS-2 transgene was sufficient for maximal activity. Endpoint PCR and quantitative PCR showed that the transgenic plants accumulated viral DNA earlier and at higher levels than wildtype plants despite considerable variation in titers between biological replicates (Fig. 2D). Viral DNA was readily detected in the transgenic plants at 14 and 21 dpi by endpoint PCR using ACMV DNA-A-specific primers. In contrast, viral DNA was first detected in wild-type plants at $28 \mathrm{dpi}$, and viral DNA levels were considerably higher at 28 and $35 \mathrm{dpi}$ in transgenic versus wild-type plants. Importantly, enhancement of symptoms and viral DNA accumulation was independent of the orientation of SEGS-2 in the Ti plasmid vector (i.e., T-S2-1.0F and T-S2-1.0R), indicating that flanking T-DNA sequences did not contribute to disease enhancement.

We used in situ hybridization to examine the pattern of ACMV infection in the presence and absence of SEGS-2. These studies used an ACMV-A oligonucleotide probe conjugated to digoxigenin that specifically binds to viral DNA and an anti-digoxigenin detection system that stains virus-positive nuclei with a dark precipitate. Petiole sections from T-S2-1.0F plants did not contain more virus-positive nuclei than wild-type plants, but the staining appeared to be stronger in T-S2-1.0F petiole sections (Fig. 2E). Stained nuclei were also observed in the leaf sections from T-S2-1.0F plants but not from wild-type plants. Many of the stained nuclei in the T-S2-1.0F leaf sections were near vascular bundles, but some were more dispersed. No staining was observed in leaf sections from the mock-inoculated controls, establishing the specificity of the in situ assay. These results suggested that SEGS-2 enhances ACMV infection by increasing the target cell population in the host.

Episomal copies of SEGS-2 in Arabidopsis thaliana. SEGS-2 episomes have been detected in infected cassava leaves and viruliferous whiteflies collected from cassava fields (38). Hence, we asked if SEGS-2 episomes also occur in Arabidopsis. Total and virion DNA preparations were used as templates for rolling-circle amplification (RCA), which preferentially amplifies small, circular DNA molecules. The RCA products were then subjected to PCR using divergent primer pairs (2-4F/2-6R) that amplify SEGS-2 episomal DNA but not genomic sequences (38) (Fig. 3A). SEGS-2 episomes were detected in ACMV-infected plants carrying the T-S2-1.0F transgene at $37 \mathrm{dpi}$ (Fig. 3B, lane 4) but not in infected wild-type plants (lane 2). When the gel image was enhanced 10-fold, a weak band corresponding to the SEGS-2 episome was also visible in mock-inoculated transgenic plants (Fig. 3B, lower, lane 3 ) but not in equivalent wild-type plants (lane 1). SEGS2 episomes were not detected in WT (Fig. 3C, lane 2)- and WT+S2-1.0 (Fig. 3C, lane 4)infected plants. We also detected SEGS-2 episomes in virion DNA from ACMV-infected T-S2-1.0F plants (Fig. 3D, lane 2) but not in samples prepared in parallel from mock-inoculated transgenic plants (lane 1). Contamination of the RCA products by $A$. thaliana genomic DNA was ruled out using the PCNA2-F/R primer pair, which amplifies a 264-bp product corresponding to the host gene (AT2G29570) encoding proliferating cell nuclear antigen (Fig. 3D, bottom).

Geminiviruses and their satellites are packaged into virions as SsDNA, prompting us to ask if the SEGS-2 DNA in virions is single stranded (9). Virion and total DNA from ACMV-infected T-S2-1.0F plants were treated with mung bean nuclease, which only digests ssDNA. After treatment, virion and total DNA were used as templates in RCA reactions followed by PCR with divergent SEGS-2 primers. SEGS-2 episomal DNA was not detected in virion DNA after mung bean nuclease treatment (Fig. 3E, lane 2), even though episomes were observed in untreated virion DNA (lane 1). In contrast, SEGS-2 episomal DNA was observed in total DNA after mung bean digestion (Fig. 3E, lane 6), albeit at lower levels than those for untreated total DNA (Fig. 3E, lane 5). These results established that SEGS-2 DNA is single stranded in virions. 

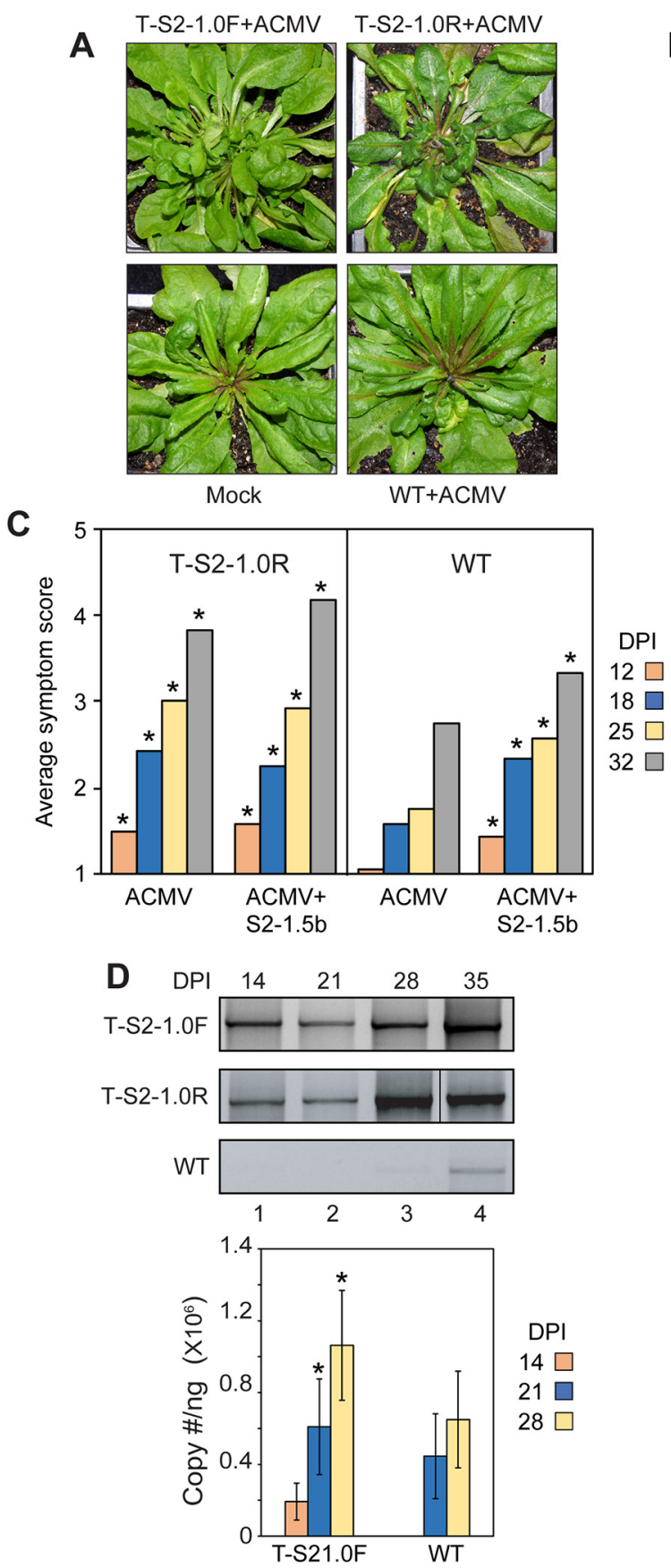

B

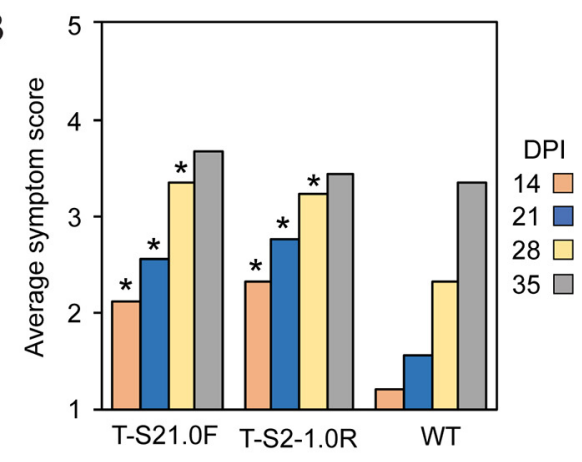

E
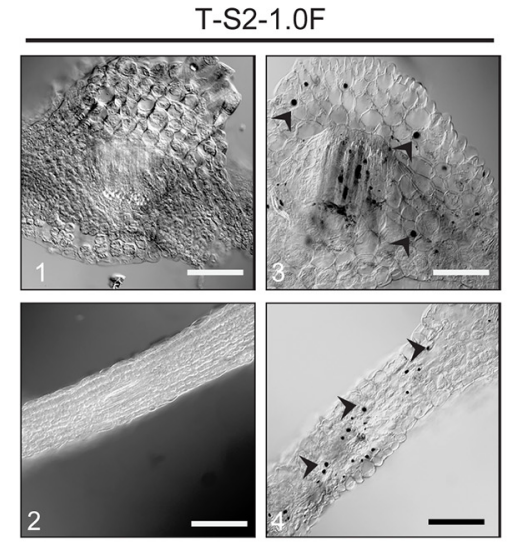

WT
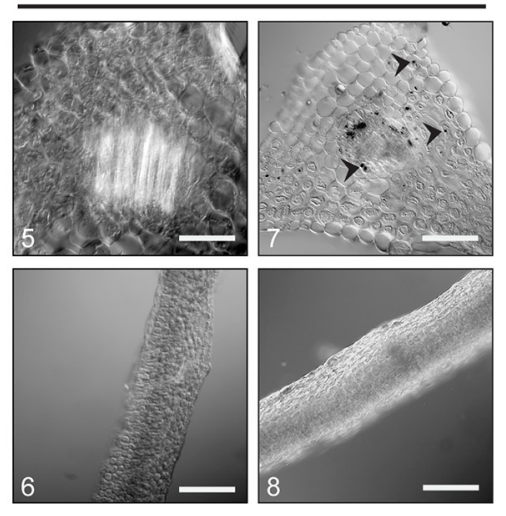

Mock

ACMV

FIG 2 SEGS-2 transgene enhances CMB infection in Arabidopsis. (A) Transgenic Sei-0 plants (T-S2-1.0F or T-S2-1.0R) inoculated with ACMV alone show severe symptoms at $28 \mathrm{dpi}$, while wild-type (WT) Sei-0 plants (WT) display mild symptoms. No symptoms were observed on plants inoculated with ACMV-B alone (mock). (B) Average symptom scores for T-S2-1.0F, T-S2-1.0R plants and wild-type Sei-0 plants inoculated with ACMV at 14, 21, 28, and 35 dpi. * $P<0.05$ from a Wilcoxon rank sum test of comparisons between SEGS-2 transgenic and wild-type plants. (C) Average symptom scores for T-S2-1.0F plants and wild-type (WT) plants inoculated with ACMV alone or with ACMV+S2-1.5b. *, $P<0.05$ from a Wilcoxon rank sum test of comparisons to wild-type plants (WT). (D) Total DNA was extracted at 14 (lane 1), 21 (lane 2), 28 (lane 3), and 35 (lane 4) dpi from T-S2-1.0F, T-S2-1.0R, and wild-type Sei-0 plants and analyzed by endpoint PCR and quantitative PCR using the CMAfor2/CMArev2 primer pair for ACMV DNA-A. The bars correspond to 2 standard errors for six biological replicates. ${ }^{*}, P<0.05$ from ANOVA test of comparisons between SEGS-2 transgenic and wild-type plants. (E) Tissue sections of T-S2-1.0F (69) and wild-type (WT; bottom) Sei-0 plants at 35 dpi incubated with a digoxigenin (DIG)-labeled DNA probe for ACMV A and visualized using an anti-DIG antibody conjugated to APconjugated antibody. Arrowheads mark infected cells containing ACMV-A DNA in their nuclei (3, 4, and 7). No viruspositive cells were observed in mock-inoculated controls (1, 2, 5, and 6) or in wild-type leaf sections inoculated with ACMV (8). Bars represent $1 \mu \mathrm{m}$ at $\times 20$ magnification. 


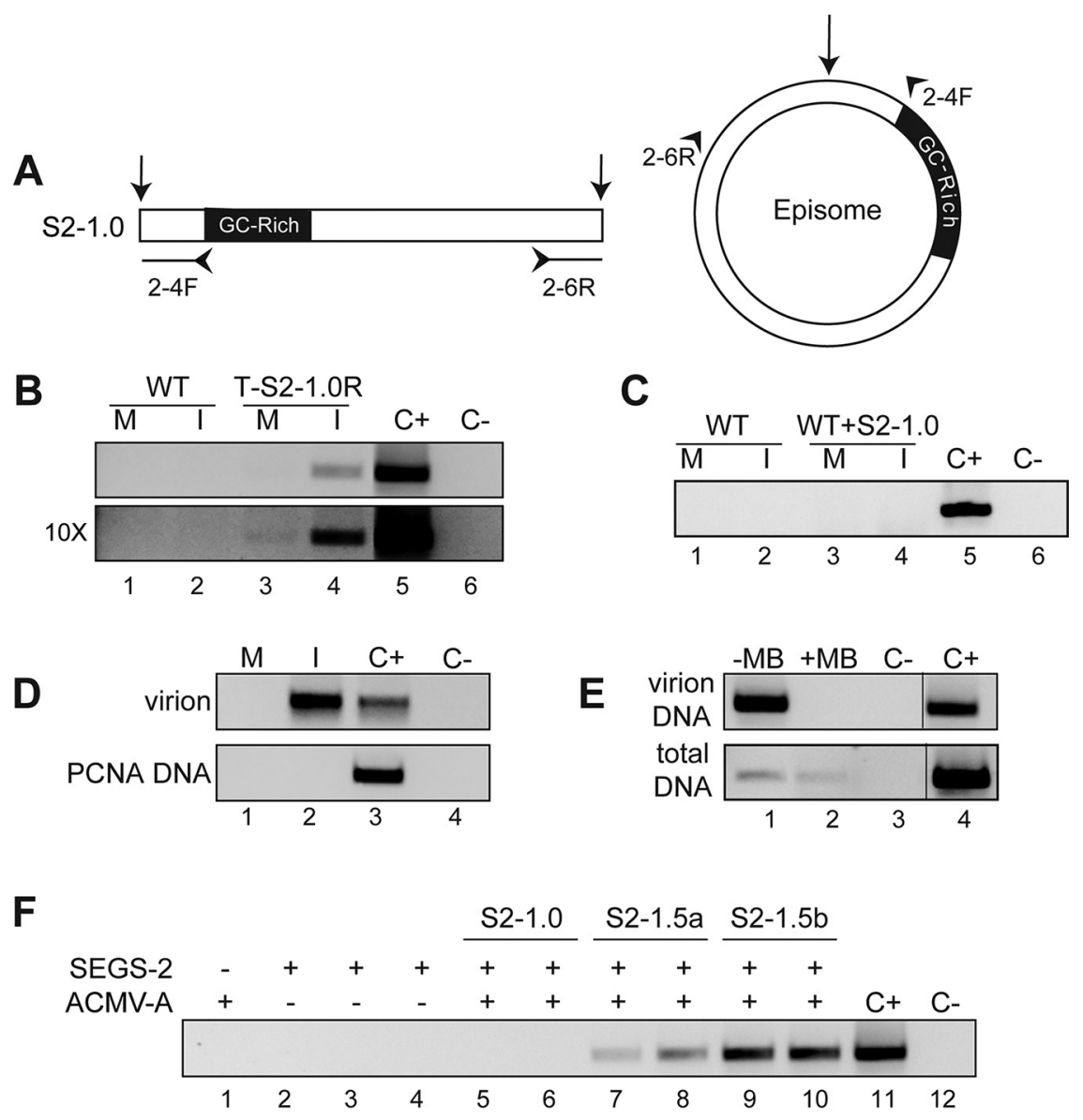

FIG 3 SEGS-2 episomes are packaged into virions. (A) The divergent primer pair 2-4F/6R (indicated by small arrowheads on the episome and linear model) was used to detect episomal copies after RCA of total DNA. The large arrows indicate the SEGS-2 episome junction site. (B) PCR products from mock (M) and ACMV-inoculated (I) wild-type (WT; lanes 1 and 2) and transgenic (T-S2-1.0R; lanes 3 and 4) Sei-0 leaves. The bottom gel, which is enhanced 10-fold, shows episomes in both mock-infected and infected T-S2-1.0R leaves (lanes 3 and 4). (C) PCR of RCA products from mock (M) and ACMVinoculated wild-type (WT; lanes 1 and 2) and WT+S2-1.0 (lanes 3 and 4) Sei-0 leaves. (D) PCR of RCA products from virion DNA of mock-inoculated $(M$, lane 1) and ACMV-infected (I, lane 2) T-S2-1.0F plants. The convergent primer pair PCNA2-F/R verified that there was no genomic DNA contamination of virion RCA template (bottom gel lanes 1 and 2). (E) PCR of RCA products of virion and total DNA treated with mung bean nuclease $(+M B$, lane 2$)$ or not treated $(-M B$, lane 1$)$. (F) Amplification of SEGS-2 episome in replication assays using protoplasts from $N$. tabacum suspension cells. Episomes were analyzed in protoplasts cotransfected with ACMV DNA-A + S2-1.0 (lanes 5 and 6), S2-1.5a (lanes 7 and 8), or S2-1.5b (lanes 9 and 10). ACMV DNA-A was transfected alone in lane 1. The SEGS-2 plasmids were transfected alone in lanes 2 (S2-1.0), 3 (S2-1.5a), and 4 (S2-1.5b). The replication assays were repeated three times. The positive control $(C+)$ used S2-1.5b plasmid DNA as the template, and the negative control $(\mathrm{C}-$ ) did not contain template DNA.

The observation that SEGS-2 episomes in total DNA samples are partially resistant to mung bean nuclease digestion is indicative of the existence of a double-stranded form. Geminivirus genomes replicate by a rolling-circle replication mechanism that involves dsDNA (10). Hence, we asked if SEGS-2 also replicates in plant cells and if its replication is dependent on the presence of a helper virus. Protoplasts from Nicotiana tabacum suspension cells were transfected with the different SEGS-2 constructs in Fig. 1A either alone or in the presence of ACMV DNA-A. Total DNA was extracted $48 \mathrm{~h}$ posttransfection, treated with Dpnl to digest DAM-methylated input plasmid DNA, and analyzed by RCA followed by PCR with the primer pair 2-4F/6R to detect SEGS-2 episomes. SEGS-2 episomes were detected when S2-1.5a (Fig. 3F, lanes 7 and 8) or S2-1.5b (lanes 9 and 10) was cotransfected with the ACMV DNA-A replicon but not when ACMV DNA-A was absent (Fig. 3F, lanes 3 and 4). No SEGS-2 episomes were detected for S2-1.0 in the 
presence (Fig. 3F, lanes 5 and 6) or absence (lane 1) of ACMV DNA-A. These results established that SEGS-2 partial tandem dimer constructs, but not a monomer construct, support replication of an SEGS-2 episome in the presence of ACMV-A in Nicotiana tabacum suspension cells. More episomal SEGS-2 DNA was detected for S2-1.5b, indicating that it contains two copies of the origin of replication (41).

The largest SEGS-2 ORF is necessary for its activity in Arabidopsis thaliana. SEGS-2 contains an open reading frame (ORF) with the capacity to encode a 75-aminoacid protein that displays $89 \%$ amino acid identity to a peptide sequence specified by the SEGS-2 partial copy, PC2-3. The small exon is located in the $5^{\prime}$ untranslated region (UTR) of a cassava gene encoding a PPR repeat protein (Manes.13G072800) (38). BLASTp analysis of public protein databases did not uncover any amino acid sequences related to the SEGS-2 protein. To directly test if ORF 2 (Fig. 4A) is necessary for SEGS-2 activity, we mutated the ATG start codon in S2-1.5b. The activity of the ATG mutant was compared to that of wild-type SEGS-2 in Sei-0 plants cobombarded with ACMV (Fig. 4B). The plants coinoculated with ACMV and S2-1.5b began to show symptoms as early as $7 \mathrm{dpi}$ (Fig. 4C) and went on to develop severe symptoms (Fig. 4B). In contrast, plants inoculated with ACMV alone or with ACMV and S2-ATGm began showing symptoms at $12 \mathrm{dpi}$ (Fig. 4C). The plants coinoculated with ACMV and S2-ATGm fell into two groups, one group (13 plants) that developed severe symptoms (S2-ATGmR) and another group (8 plants) that only showed mild symptoms (S2-ATGm), similar to plants inoculated with ACMV alone (Fig. 4B). DNA sequencing revealed that ATG mutation in the SEGS-2 ORF had reverted to wild type in the plants with severe symptoms, while SEGS-2 could not be detected in plants with mild symptoms.

Transcriptional analysis of SEGS-2 in transgenic lines. We next asked if SEGS-2 is transcribed in plants using reverse transcription-PCR (RT-PCR) and rapid amplification of CDNA ends (RACE). An 825-bp product was amplified from total RNA from healthy T-S21.0F and T-S2-1.0R plants by RT-PCR using the 2-hp1f/2-2BR primer pair (Fig. 5B). Detection of the product was independent of the orientation of the SEGS-2 insert in the T-DNA plasmid. The direction of transcription was determined using a 5' RACE reaction. A 532-bp product (Fig. 5C, lane 2) matching the predicted size (positive control, lane 3) was observed using the LGSP1/2 primer pair in the LR (left to right) reaction. The band (Fig. 5C, lane 1) in the RR (right to left) reaction with the RGSP1/2 primers is of similar size to the band in the no template control (lane 4). Sequencing of the products from the two RACE reactions confirmed that the band in the LR reaction corresponds to SEGS2 , while the band in the RR reaction is nonspecific. Thus, transcription is oriented in the same direction as the SEG-2 ORF (Fig. 5A).

We then examined SEGS-2 transcripts during ACMV infection at 37 dpi using RTPCR and the primer pair 2-hp1f/2-2BR. An 825-bp product was observed in total RNA from infected T-S2-1.0F plants (Fig. 5D, lane 4). More SEGS-2 RNA was detected in infected than mock-inoculated T-S2-1.0F plants (Fig. 5D, lanes 3 and 4). No SEGS-2 transcripts were detected in total RNA samples from mock-inoculated (Fig. 5D; lane 1) or infected (lane 2) wild-type plants.

The 5' RACE product of the SEGS-2 transcript extended to the junction of the SEGS2 insert and T-DNA vector. Given that detection of the SEGS-2 transcript was independent of the orientation of the SEGS-2 insert in the T-DNA (Fig. 5B), it was not clear what promoter sequences support SEGS-2 transcription. One possibility is that when SEGS-2 forms an episome, a sequence downstream of the transcript in the linear sequence functions as a promoter (Fig. 5A). To test this, we generated expression cassettes in which a 971-bp sequence from the stop codon to the 5' ATG of the SEGS-2 ORF was inserted upstream of a luciferase reporter in both orientations (Fig. 5A). The cassettes were transfected into Nicotiana tabacum protoplasts, and luciferase activity was measured $36 \mathrm{~h}$ posttransfection (Fig. 5E). The sequence with the same orientation as the SEGS-2 ORF (P:S2-F) supported luciferase expression that was significantly above that of the empty vector control (Student $t$ test with $P$ value of $<0.05$ ). In contrast, the reverse orientation ( $\mathrm{P}: \mathrm{S} 2-\mathrm{R})$ did not support luciferase expression. The amount of luciferase activity supported by the P:S2-F fragment was ca. 100-fold less than that of the 
A

GC-Rich

SEGS-2 ORF

ATGm

B

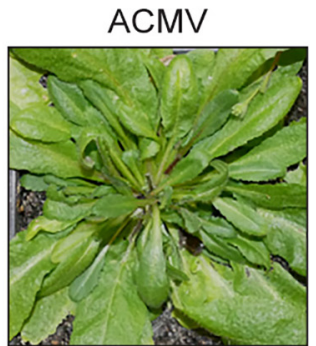

$\mathrm{ACMV}+\mathrm{S} 2-1.5 \mathrm{~b}$
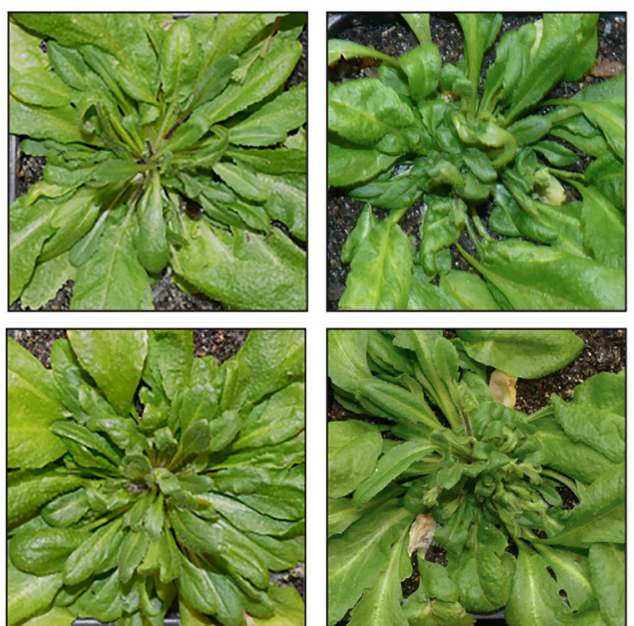

ACMV+S2-ATGm

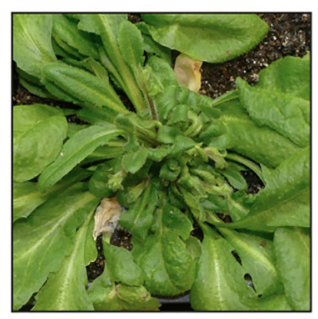

ACMV+S2-ATGmR

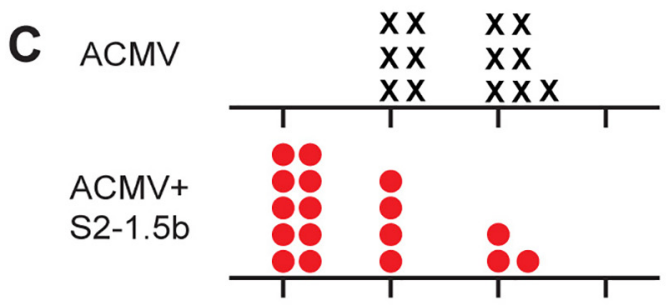

ACMV+ S2-ATGm

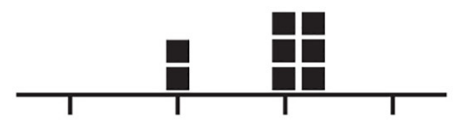

ACMV+ S2-ATGmR

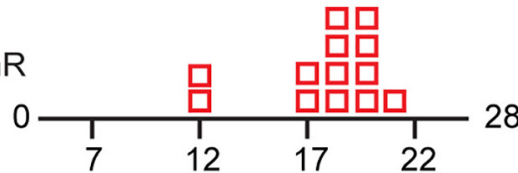

Day of symptom appearance

Mild Symptoms

Severe Symproms

FIG 4 SEGS-2 encodes a functional open reading frame (ORF). (A) Diagram of the longest SEGS-2 ORF with mutated ATG indicated by an arrow. (B) Arabidopsis Sei-0 plants inoculated with ACMV DNA-A and DNA-B alone or in combination with wild-type S2-1.5b or the ATG mutant (S2-ATGm) plasmid at 28 dpi. (C) Day of symptom appearance for individual plants with ACMV (X), ACMV + S2-1.5b (circle), ACMV + S2-ATGm (closed square), and ACMV + S2-ATGmRevertant (open square). Red indicates plants showing severe symptoms, and black indicates mild symptoms.

strong enhanced 35 S promoter (E35S), indicating that the SEGS-2 promoter is of moderate strength. Inclusion of ACMV DNA-A in the transfection reactions did not increase the activity of the SEGS-2 promoter (not shown).

SEGS-2 enhances geminivirus infection in a resistant Arabidopsis thaliana accession. Pla- 1 is an $A$. thaliana accession that is resistant to cabbage leaf curl virus (CaLCuV) infection (42). We asked if CaLCuV can infect Pla-1 plants when it is coinoculated 

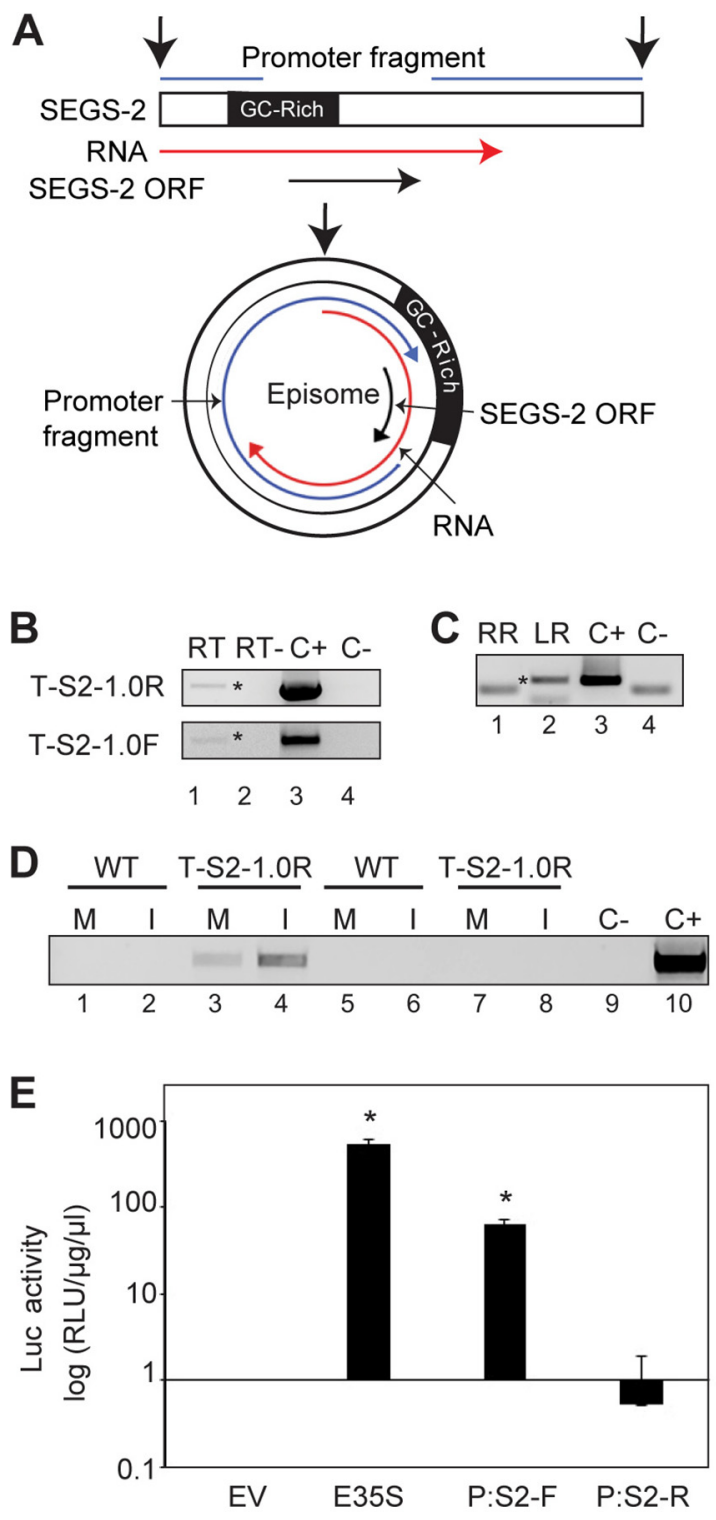

FIG 5 SEGS-2 transcription in healthy and infected plants. (A) Diagram of SEGS-2 transcription unit. Linear and episomal maps of SEGS-2 are shown, with the episomal junction marked by the vertical black arrows. The SEGS-2 ORF is marked by the horizontal and circular black arrows. The 825-bp SEGS-2 RNA is indicated by the red arrows The formation of the SEGS-2 episome brings a promoter (blue lines and arrow) in the $3^{\prime}$ end of linear SEGS-2 sequence to the $5^{\prime}$ end of the SEGS-2 ORF. (B) CDNA from total RNA extracted from healthy S2-1.0F and S2-1.0R (bottom) plants was amplified using convergent primer pairs, S2 hp1F/2BR and $\mathrm{S} 2$ 7F/2R, respectively (RT, lane 1). The negative control did not include reverse transcriptase during cDNA synthesis (RT-, lane 2). (C) PCR of 5' RACE reaction to the right (RR, lane 1) and left (LR, lane 2) with primer pair S2 hp1F/RGSP2. Asterisks in panels B and C indicate the SEGS-2 product. (D) RT-PCR (lanes 1 to 4) with primer pair S2 hp1F/2BR of cDNA from total RNA extracted (lanes 5 to 8) from wild-type Sei-0 (WT; lanes 1, 2, 5, and 6) and T-S2-1.0R (lanes 3, 4, 7, and 8) leaves in mock (M)- and ACMV-inoculated (I) leaves. Lanes 5 to 8 are no reverse transcriptase negative controls. In panels $B, C$, and D, the positive control $(C+)$ used S21.0 plasmid DNA as the template, and the negative control $(C-)$ did not contain template. (E) Luciferase activity in tobacco protoplasts at $36 \mathrm{~h}$ after transfection with the forward (P:S2-F) and reverse (P:S2-R) orientation of the noncoding regions of SEGS-2 cloned upstream of the Luc gene. The E35S promoter and the empty vector (EV) are the positive and negative controls. Both P:S2-F and the E35S promoter displayed significant Luc activity compared to the EV control in a Student's $t$ test (asterisks; $P<0.05$ ). P:S2-R does not support Luc expression. Error bars correspond to two standard errors.

with SEGS-2. Pla-1 plants cobombarded with CaLCuV and S2-1.5a or S2-1.5b displayed symptoms at 21 and 30 dpi (Fig. 6A) and showed no signs of flowering at 50 dpi (Fig. 6B). Consistent with the symptom results, viral DNA was detected at 29 and 43 dpi in plants coinoculated with CaLCuV and SEGS-2 (Fig. 6C). In contrast, Pla-1 plants inoculated with 
A

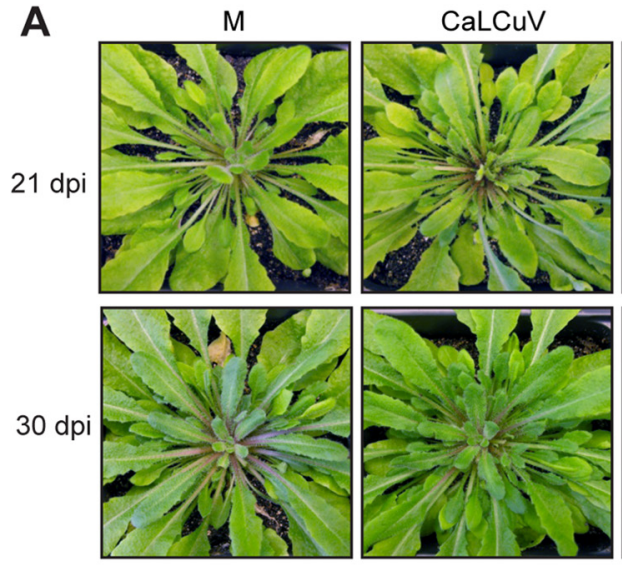

CaLCuV+S2-1.5a

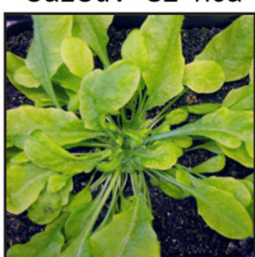

$\mathrm{CaLCuV}+\mathrm{S} 2-1.5 \mathrm{~b}$
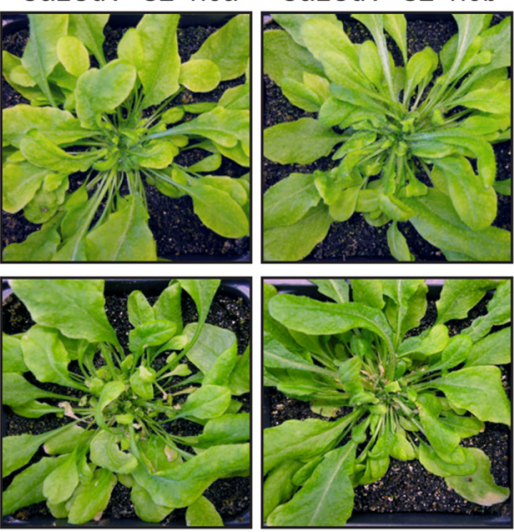

B

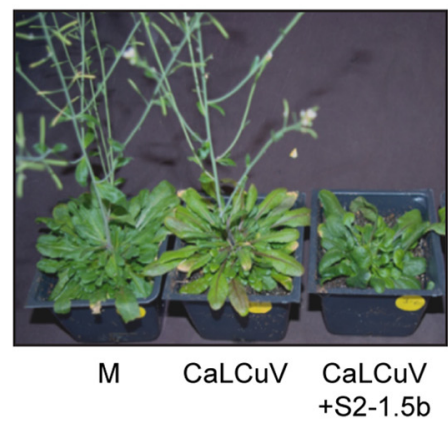

C

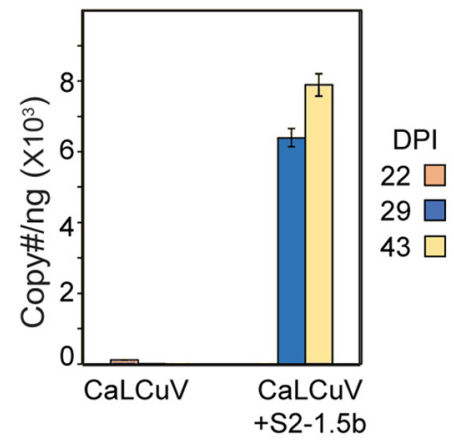

D
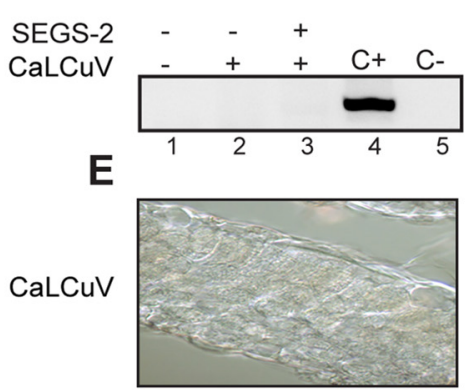

CaLCuV $+\mathrm{S} 2-1.5 \mathrm{~b}$

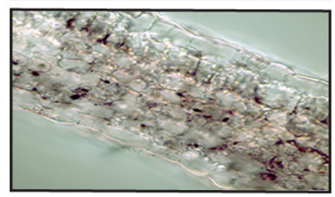

F
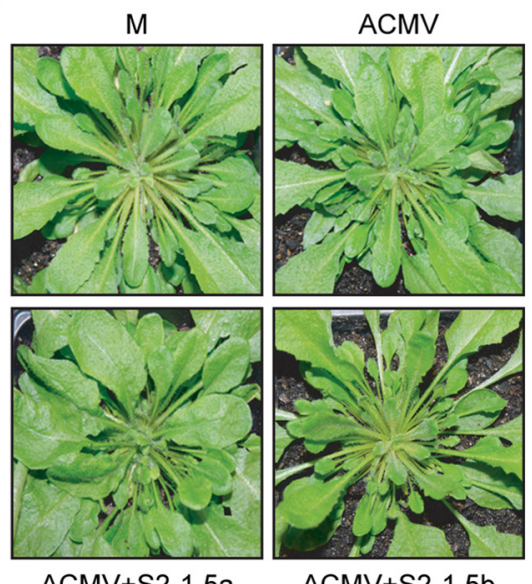

FIG 6 SEGS-2 facilitates CaLCuV infection of a resistant Arabidopsis accession. (A) Pla-1 plants inoculated with CaLCuV DNA-A and DNA-B alone or in combination with $\mathrm{S2}-2.5 \mathrm{a}$ or S2-1.5b plasmid at 21 and 30 dpi. (B) Flowering is suppressed in Pla-1 plants coinoculated with CaLCuV and S2-1.5b but not with CaLCuV alone at $50 \mathrm{dpi}$. (C) Viral copy number determined by quantitative PCR of CaLCuV-A at 22, 29, and 43 dpi. The bars correspond to 2 standard errors for three replicates. (D) PCR of RCA products for episomal copies from mock (lane 1)-, CaLCuV (lane 2)-, and CaLCuV+S2-1.5b (lane 3)-infected leaves. (E) Immunolocalization of CaLCuV Rep in Pla-1 leaf sections infected with CaLCuV alone or in combination with S2-1.5b at 36 dpi. CaLCuV Rep was only observed in leaves coinoculated with CaLCuV and S2-1.5b. (F) Pla-1 plants inoculated with ACMV alone or in combination with S2-1.5a or S2-1.5b did not show symptoms at 30 dpi.

CaLCuV alone resembled mock-inoculated plants in that they did not show symptoms or contain viral DNA (Fig. 6A to C). SEGS-2 episomes were not detected in Pla-1 coinoculated with CaLCuV and S2-1.5a (Fig. 6D, lane 3). Immunochemistry analysis showed that the viral Rep protein was distributed throughout leaves from Pla-1 plants coinoculated with CaLCuV and S2-1.5a but could not be detected in leaves from plants only inoculated with 
CaLCuV (Fig. 6E). We also asked if ACMV can infect Pla-1 plants in the presence of SEGS-2. We failed to detect any symptoms when ACMV was cobombarded with S2-1.5a or S2-1.5b (Fig. 6F).

\section{DISCUSSION}

Begomovirus-associated betasatellites, as well as least one alphasatellite, enhance symptom severity and viral DNA accumulation $(25,26,29,35,43,44)$. In an earlier study, we showed that SEGS-2, a sequence that was amplified from CMD-infected cassava in Tanzania, also causes more severe symptoms during CMB infection of cassava (38). SEGS-2 occurs as a circular episome in infected cassava and is packaged into virions, consistent with it being a DNA satellite. However, it has been difficult to study SEGS-2 in cassava because of the widespread presence of SEGS-2-related sequences in the cassava genome. To overcome this complication, we used heterologous plant systems to characterize SEGS2 functions in the absence of endogenous genomic sequences. We showed that like cassava, $A$. thaliana plants infected with ACMV in the presence of SEGS-2 develop curling and filiform leaf symptoms. Symptom enhancement is dependent on maintenance of the largest ORF in SEGS-2. SEGS-2 also forms episomes that are transcribed and packaged as ssDNA into virions in A. thaliana and replicates in the presence of ACMV-A in tobacco cells. These properties strongly support our hypothesis that SEGS-2 is a new type of begomovirus satellite that contributes to increased CMD severity in sub-Saharan Africa.

SEGS-2 increased ACMV symptoms in A. thaliana when it was provided exogenously from a plasmid (Fig. 1) or from a transgene (Fig. 2). Plants coinoculated with ACMV and the SEGS-2 monomer (S2-1.0) or partial tandem dimer clones (S2-1.5a or S2-1.5b) displayed stronger symptoms that appeared sooner compared to plants inoculated with ACMV alone. The configuration of the SEGS-2 clones had small but reproducible effects on symptoms later in infection, with S2-1.0 showing milder symptoms and a delay in appearance relative to S2-1.5a and S2-1.5b (Fig. 1D and E). The S2-1.5a and S2-1.5b clones were designed to resemble begomovirus partial tandem infectious clones, which are released from bacterial plasmid vectors via replication or recombination (41). The same mechanisms could provide a rationale for why $\mathrm{S} 2-1.5 \mathrm{a}$ and $\mathrm{S2}-1.5 \mathrm{~b}$ show more symptom enhancement than S2-1.0.

Transgenic Arabidopsis carrying an SEGS-2 monomer sequence developed symptoms and accumulated viral DNA earlier and to higher levels than wild-type plants (Fig. 2B and D). These phenomena were independent of the orientation of the transgene, indicating that T-DNA sequences did not impact SEGS-2 activity. Unexpectedly, T-S2-1.0 plants inoculated with ACMV alone displayed stronger symptoms than plants inoculated with exogenous S2-1.5b+ACMV (Fig. 2C). This may be due to the presence of the SEGS-2 transgene in every plant cell that is infected by the virus, which is unlikely when SEGS-2 is provided exogenously. Cobombardment of S2-1.5b with ACMV in T-S2-1.0 plants did not increase symptoms compared to T-S2-1.0 plants inoculated only with ACMV, indicating that the transgene effect on symptoms was maximal and could not be further enhanced by the addition of exogenous SEGS-2 DNA (Fig. 2C). Together, these results support the idea that the availability of SEGS-2 throughout the plant is responsible for the stronger effect in transgenic Arabidopsis.

Earlier studies showed that the Pla-1 accession of $A$. thaliana is immune to CaLCuV infection (42). We showed that CaLCuV can infect Pla-1 plants in the presence of exogenous SEGS-2 (Fig. 6). This result was unexpected, because studies in cassava indicated that SEGS-2 cannot overcome CMD2 resistance to CMBs (38). This difference may reflect dissimilarities in the resistance mechanisms that are not yet known for either Arabidopsis or cassava. The ability of SEGS-2 to assist CaLCuV infection in overcoming resistance indicated that its activity is not specific for CMB infection and, instead, is likely an effect on a general feature of the begomovirus infection process. An interesting feature of CaLCuV infection in Pla-1 is the presence of virus throughout the leaf in the presence of SEGS-2 (Fig. 6E). In the susceptible accession Col-0, CaLCuV is vascular associated and is not commonly seen in mesophyll or epidermal cells (45). It is not 
known if the lack of detectable virus in Pla-1 plants in the absence of SEGS-2 is due to inhibition of viral replication or movement of virus out of the inoculated cell. The widespread distribution of CaLCuV in the presence of SEGS-2 in Pla-1 suggests that SEGS-2 breaks resistance by overcoming a barrier to viral cell-to-cell movement. It is noteworthy that ACMV cannot infect Pla-1 in the presence of SEGS-2 (Fig. 6F), suggesting that the barrier to infection is greater for a virus poorly adapted to Arabidopsis.

An earlier study showed that SEGS-2 episomes are encapsidated into virions in CMBinfected cassava plants and viruliferous whiteflies (38). ACMV-infected $A$. thaliana with a SEGS-2 transgene also contained SEGS-2 episomes (Fig. 3B) that were packaged into virions (Fig. 3D). We extended these observations by showing that SEGS-2 is packaged as ssDNA in A. thaliana. At $1.2 \mathrm{~kb}, \mathrm{SEGS}-2$ is similar in size to other begomovirus satellites, which are also encapsidated into virions as ssDNA $(46,47)$. SEGS-2 also occurs as a dsDNA in $A$. thaliana leaves, characteristic of rolling-circle and/or recombination-dependent replication $(13,48)$ (Fig. 3E). SEGS-2 episomes were not found in WT (Fig. 3C) or Pla-1 (Fig. 6D) plants coinoculated with SEGS-2, indicating that local expression of SEGS-2 was not sufficient for episome formation. Replication assays in tobacco protoplasts established that SEGS-2 can replicate in the presence of ACMV-A (Fig. 3F), analogous to betasatellites, which also rely on begomovirus helper viruses for their replication $(29,49)$. DNA minicircles, which consist of both viral and host DNA, have been identified in begomovirusinfected plants (50). Like SEGS-2, the minicircles, which are packaged into virions, can also replicate in the presence of a helper begomovirus. However, they differ from SEGS-2 in that they contain viral DNA with an origin of replication, while SEGS-2 does not contain a recognizable viral replication origin.

The replication properties of the different SEGS-2 clones may provide some insight into the origin of replication in SEGS-2. S2-1.5a and S2-1.5b replicated in the presence of ACMV-A, but no replication was detected for S2-1.0. In addition, S2-1.5b replicated to higher levels than S2-1.5a. S2-1.5a and S2-1.5b contain a 21-bp inverted repeat with a 4-bp loop that includes the SEGS-2 episomal junction. The 3' stem sequence, which does not occur in the cassava genome, shows strong similarity to alphasatellite origin sequences (38). S2-1.0 does not include the stem-loop, because the 21-bp sequences are separated by intervening SEGS-2 sequences in the cloned DNA. If the hairpin is involved in SEGS-2 replication, this would provide an explanation for why S2-1.0 did not replicate in the transient assays. The difference between S2-1.5a and S2-1.5b may reflect that different regions of SEGS-2 are duplicated in the partial tandem dimers. If S2-1.5b contains two functional origins flanking SEGS-2 sequences, this configuration would facilitate replicational release of an episome. In contrast, without two functional origins, S2-1.5a could release an SEGS-2 episome via recombination between the duplicated sequences, a process that is less efficient than replicational release (41). The result would be the detection of more nascent SEGS-2 DNA for S2-1.5b than for S2-1.5a in the replication assays.

The observation that the S2-1.0 clone does not replicate in transient replication assays raises the question of why the SEGS-2 monomer forms episomes during infection in A. thaliana. Although the 21-bp sequences at the ends of the SEGS-2 inserted in S2-1.0 do not facilitate episome formation during the 48-h replication assays, they may enable episome formation over longer periods of time in transgenic T-S2-1.0 plants. The detection of SEGS-2 episomes at very low levels in mock-inoculated T-S2-1.0 plants established that SEGS-2 episome formation is not dependent on virus infection and, instead, is a property inherent in the SEGS-2 monomer sequence. SEGS-2 episomes could have been generated at any time during growth of T-S2-1.0 plants or in response to wounding during bombardment $(51,52)$. A change in DNA methylation status due to wounding may trigger the release of the SEGS-2 monomer at the site of the inverted repeats and the formation of an episome (53). The presence of SEGS-2 episomes in mock-inoculated plants also provides an explanation for the detection of SEGS-2 RNA in the mock controls. Once generated, SEGS-2 episomes can undergo replication 
during ACMV infection, resulting in the observed increase for both episomes and SEGS-2 RNA in infected plants.

Like betasatellites, SEGS-2 encodes a small protein that is necessary for its activity in Arabidopsis $(29,49)$. Analysis of SEGS-2 ATG mutants uncovered two ACMV infection phenotypes, one with mild symptoms and one with severe symptoms (Fig. 4B). The timing of symptom appearance was delayed for the severe symptom class compared to the wild-type SEGS-2 control (Fig. 4C). Sequencing revealed that the SEGS-2 mutation had undergone reversion restoring the SEGS-2 ORF in all of the plants with severe symptoms. High levels of reversion have also been reported for AC1 mutants in tomato golden mosaic virus (54). In that case, the mutant $A C 1$ virus reverted in all infected plants within 3 weeks, reflecting strong selection pressure to restore interactions between the viral Rep protein and a host protein necessary for efficient viral replication (55). Reversion of the SEGS-2 ORF did not occur in all plants, most likely because, unlike Rep, the SEGS-2 protein is not essential for begomovirus infection. However, the high level of reversion supports the importance of the SEGS-2 ORF during infection of a poorly adapted virus like ACMV in A. thaliana.

The SEGS-2 ORF specifies a protein containing 75 amino acids. The cassava genome contains two small ORFs with the potential to encode 69 amino acid proteins with high similarity to SEGS-2. The small ORFs are located within a 38-kb region on chromosome 13 that includes the previously identified SEGS-2 partial copies, PC2-2 and PC2-3 (38). The PC2-2 and PC2-3 ORFs show $85 \%$ and $89 \%$ amino acid identity, respectively, to the SEGS-2 ORF (38). The PC2-2 ORF is not associated with a cassava gene, and there is no evidence that it is transcribed. In contrast, the PC2-3 ORF is located in the 5' UTR of an mRNA transcribed from a cassava gene encoding a PPR repeat protein (Manes.13G072800). Small ORFs in 5' UTRs have been implicated in negative control of translation, and they can impact protein expression in a variety of plant processes, including the host defense response (56). SEGS-2-related sequences in the cassava genome are often found in 5' UTRs, suggesting that they are involved in translational control of many genes. However, it is not known if the proteins specified by PC2-2 and PC2-3 have roles other than translational control, analogous to the SEGS-2 protein (38).

Our results support a model in which SEGS-2 was generated by a recombination event between a cassava genomic sequence and an alphasatellite (Fig. 7). The recombinant DNA forms an episome that is enscapsidated into virions as ssDNA. SEGS-2 also exists as a dsDNA that is formed during replication in the presence of a helper virus. SEGS-2 encodes an ORF that is transcribed from the viral dsDNA template. The SEGS-2 ORF specifies a small protein that enhances symptoms, potentially by altering cell-to-cell movement of viral DNA. Taken together, we propose that SEGS-2 represents a new type of low-copy-number begomovirus satellite with the capacity to enhance disease and break resistance. Future studies that focus on the interactions of SEGS-2 with CMBs and cassava may contribute to the development of effective and sustainable disease control measures for CMD.

\section{MATERIALS AND METHODS}

Cloning. All of the plasmids and primers used in this study are listed in Table 1 (see also Table S1 in the supplemental material). All of the clones and mutants were confirmed by Sanger sequencing.

The SEGS-2 clones were generated from a pGEM-T Easy plasmid harboring a dimeric copy of SEGS-2 (pGEM-2SEGS-2) (38). pGEN-2SEGS-2 was digested with EcoRI to release the dimer and ligated into pUC119, also cut with EcoRl, to create pNSB2137. A 1,197-bp SEGS-2 sequence in pNSB2137 was released using BamHI and ligated into pUC119 linearized with BamHI to generate the monomer clone S2-1.0 (pNSB2001). S2-1.5a (pNSB1870) and S2-1.5b (pNSB1869) are partial tandem dimer clones with one full copy of SEGS-2 and duplicated sequences corresponding to SEGS-2 positions 1 to 449 and 449 to 1197, respectively. A 586-bp SEGS-2 sequence was released from pNSB2137 as an Ndel-repaired/Nsil fragment and ligated into pUC119 digested with Pstl and Smal to generate pNSB1868. A 748-bp fragment was released from pNSB2001 as a BamHI/Ndel-repaired fragment and ligated into pUC119 digested with BamHI and Smal to generate pNSB1867. pNSB2001 was digested with BamHI to release a 1,197-bp SEGS-2 fragment and ligated into both pNSB1868 and pNSB1867, also digested with BamHI, to give S2-1.5a (pNSB1870) and S2-1.5b (pNSB1869), respectively. The SEGS-2 ATG mutant (pNSB2110) was created in S2-1.5b (pNSB1869) using the QuikChange II site-directed mutagenesis kit (Agilent Technologies) and the primers SEGS-2MutF/SEGS-2MutR. 


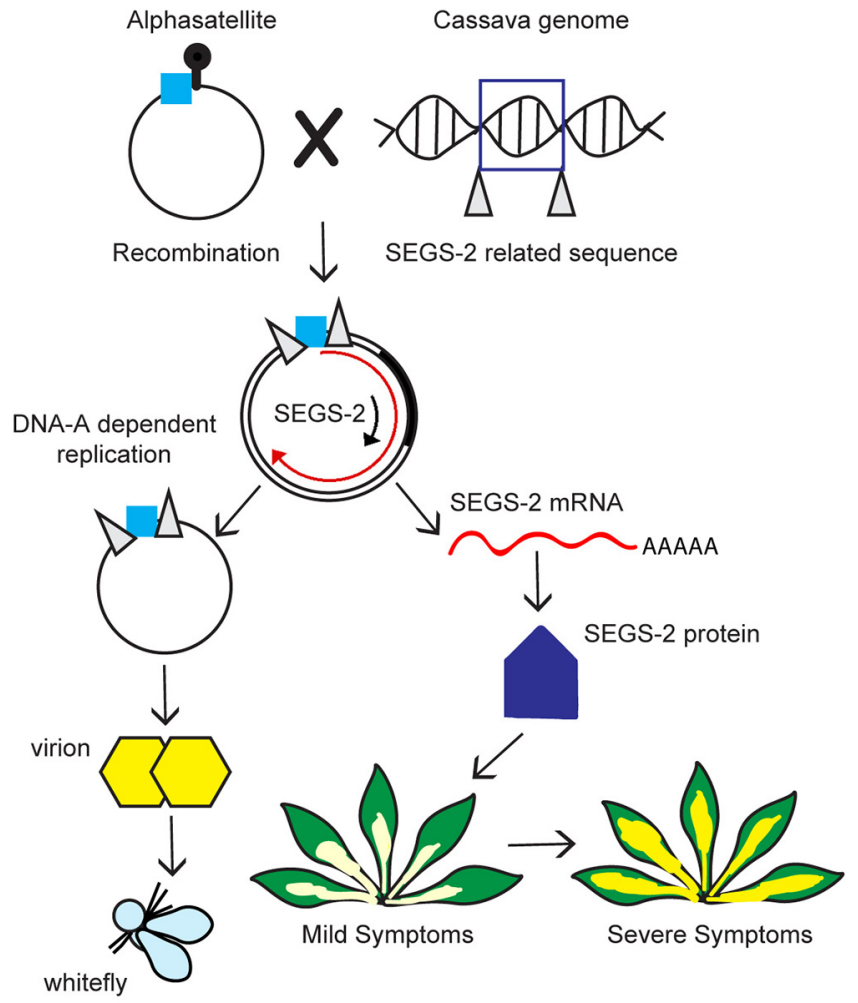

FIG 7 Model of SEGS-2 biology. A SEGS-2 sequence in the cassava genome recombined with an alphasatellite and acquired a small fragment adjacent to the satellite origin of replication (blue box). The alphasatellite sequence may facilitate rolling-circle replication of a circular SEGS-2 episome in the presence of a CMB helper virus. The SEGS-2 episome is packaged into virions and transmitted by whiteflies as part of the CMB virus complex. The SEGS-2 episome is transcribed and the RNA is translated to produce a 75 -amino-acid protein that is necessary for the enhancement of geminivirus symptoms.

Notl sites were introduced at the ends of the S2-1.0 insert in pNSB2001 using the QuikChange II sitedirected mutagenesis kit and the primers mb1f/1r-mb8f/8r (Table S1). The resulting fragment was digested with Notl to release the SEGS-2 fragment, which was cloned into the T-DNA plasmid pMON721 linearized with Notl to give T-S2-1.0 (pNSB1999F/R). The orientation of the SEGS-2 insert in the vector

TABLE 1 Plasmids used for plant studies

\begin{tabular}{|c|c|c|c|c|}
\hline Name & Description & Vector & Primers $^{a}$ & Clone no. \\
\hline \multicolumn{5}{|l|}{ SEGS-2 plasmids } \\
\hline S2-1.0 & SEGS-2 Monomer & pUC119 & & pNSB2001 \\
\hline S2-1.5a & SEGS-2 1.5a & pUC119 & & pNSB1870 \\
\hline $\mathrm{S} 2-1.5 \mathrm{~b}$ & SEGS-2 1.5b & pUC119 & & pNSB1869 \\
\hline S2-1.5bmATG & ATG ORF Mutant & pUC19 & SEGS-2MutF, SEGS-2MutR & pNSB2110 \\
\hline \multicolumn{5}{|c|}{ Infectious viral clones } \\
\hline pILTAB409 & ACMV DNA-A & pBluescriptllKS- & & pILTAB409 \\
\hline pILTAB410 & ACMV DNA-B & pBluescriptllKS- & & pILTAB410 \\
\hline pNSB1090 & CaLCuV DNA-A & pCpCLCV A.003 & & pNSB1090 \\
\hline pNSB1091 & CaLCuV DNA-B & pCpCLCV A.003 & & pNSB1091 \\
\hline \multicolumn{5}{|l|}{ T-DNA plasmids } \\
\hline $\mathrm{T}-\mathrm{S} 2-1.0 \mathrm{~F}$ & SEGS-2 Monomer & pMON721 & $m b 1 f / 1 r, m b 8 f / 8 r$ & pNSB1999F \\
\hline $\mathrm{T}-\mathrm{S} 2-1.0 \mathrm{R}$ & SEGS-2 Monomer & pMON721 & $m b 1 f / 1 r, m b 8 f / 8 r$ & pNSB1999R \\
\hline \multicolumn{5}{|l|}{ Reporter plasmids } \\
\hline EV & No promoter & pNSB8796 & & pNSB2111 \\
\hline E35S & Enhanced 355 promoter sequence & pMON999 & & pMON8796 \\
\hline$P: S 2 F$ & SEGS-2 promoter sequence forward & pNSB8796 & PSTlucF/BcLllucF & pNSB2112 \\
\hline $\mathrm{P}: S 2 \mathrm{R}$ & SEGS-2 promoter sequence reverse & pNSB8796 & S2_ORF_Fwd/Rev & pNSB2113 \\
\hline
\end{tabular}

aprimers used for cloning and mutagenesis. 
was determined by Pstl digestion. Agrobacterium tumefaciens strain ABI was transformed via electroporation with both the forward (T-S2-1.0F) and reverse (T-S2-1.0R) orientations (57) (Table S1).

The P:S2-F luciferase reporter cassette (pNSB1949) was generated from pMON1869 using the primers PST_Promoter_Luciferase/BCII_Promoter_Luciferase (Table S1). The resulting 973-bp fragment was digested with Pstl and Bcll and ligated upstream of the luciferase coding sequence in pMON8796, which was first digested with Pstl and BCll to remove the E35S promoter. The P:S2-R cassette was inserted into pMON8796 using the NEB Builder kit with primer pair S2-ORF_Fwd/Rev to amplify the 973-bp cassette. pMON9708empty_Fwd/Rev was used to amplify the pMON8796 vector with matching overlapping ends to the P:S2-R cassette by following the NEB Builder kit protocol (Table S1).

Arabidopsis transformation. The Arabidopsis thaliana accession Sei-0 from the Arabidopsis Biological Resource Center (ABRC; stock number CS1504; Ohio State University) was transformed using the floral dip method (58) to introduce T-S2-1.0F and T-S2-1.0R. Seeds of $A$. thaliana transformants were sterilized in 1.5$\mathrm{ml}$ Eppendorf tubes with $70 \%$ ethanol for $2 \mathrm{~min}$, followed by treatment with a $5 \%$ bleach solution containing $0.02 \%$ Triton X-100 for 10 min and washing 3 times with sterile water. Approximately 100 sterile seeds were placed on selection plates (MSO medium with $0.5 \mathrm{mg} / \mathrm{ml}$ kanamycin) and sealed with aeration tape. The plates were placed in the dark at $4^{\circ} \mathrm{C}$ for 2 days, followed by a brief exposure to light for $6 \mathrm{~h}$ at room temperature, and incubated again for 2 days in the dark at $4^{\circ} \mathrm{C}$ until the seeds began to germinate. The plates were then placed in constant light at room temperature for plantlet growth. Three sequential generations were screened for kanamycin resistance. The second generation (T2) of seeds that showed 3:1 segregation was screened to identify homozygous lines in the third generation (T3).

Infection assays. Plants corresponding to the $A$. thaliana accessions Sei- 0 , Col-0, and Pla- 1 were grown at $20^{\circ} \mathrm{C}$ under 8-h light/16-h dark cycles. For infection, 6- to 7-week-old plants with ca. 30 leaves were inoculated using a microsprayer at $30 \mathrm{lb} / \mathrm{in}^{2}$ to deliver gold particles coated with SEGS-2 plasmids (600 ng/6 plants) alone or in combination with infectious clones for ACMV (5 $\mu \mathrm{g}$ each of DNA-A and DNA-B/ 6 plants; GenBank accession numbers MT858793.1 and MT858794.1 [59]) or CaLCuV (2.5 $\mu \mathrm{g}$ each of DNA-A and DNA-B/ 6 plants; accession numbers U65529.2 and U65530.2 [60]). Nine plants were inoculated for each DNA combination treatment, and a mock inoculation control was included for each experiment. All experiments were repeated three times. Disease symptoms were monitored visually starting at $7 \mathrm{dpi}$ and continuing for up to $35 \mathrm{dpi}$. Symptoms, including chlorosis, leaf deformation, and stunting, were scored on a 1 to 5 symptom severity scale (1, no symptoms; 5 , very severe) throughout new growth in the rosette. Total DNA was isolated from Arabidopsis plants at 7, 14, 21, 28, and 35 dpi using the CTAB protocol (61). ACMV or CaLCuV DNA-A accumulation was characterized in total DNA $(0.1 \mu \mathrm{g})$ samples by semiquantitative PCR using the primer pairs CMAFor2/CMARev2 and CaLCuV-For/ CaLCuV-Rev, respectively. Both primer sets consisted of divergent primers that only amplified circular DNA-A molecules released from infectious clone DNA efficiently. For CaLCuV, PCR using standard Taq polymerase (NEB) was performed for 30 cycles (denaturation, $45 \mathrm{~s}$ at $95^{\circ} \mathrm{C}$; annealing, $45 \mathrm{~s}$ at $53^{\circ} \mathrm{C}$; extension, $2.25 \mathrm{~min}$ at $72^{\circ} \mathrm{C}$ ). PCR conditions for ACMV were similar, except the annealing temperature was $55^{\circ} \mathrm{C}$ and Hot Start Taq polymerase (NEB) optimized for large product sizes was used. The PCR products (885 bp for CaLCuV and 2,593 bp for ACMV) were resolved on 1\% (wt/vol) agarose gels and stained with ethidium bromide for UV light visualization. The concentration of ACMV DNA-A (primer pair P3P-AA2F and P3P-AA2R + 4R; Table S1) and CaLCuV DNA-A (primer pair CaLCuV1990-F and CaLCuV1990-R; Table S1) was also determined using quantitative PCR by following Aimone et al. (62) and Rajabu et al. (63) for ACMV and CaLCuV, respectively. Statistical analysis was performed using SAS University Edition 3.8. A generalized linear mixed model was used to test for significant effects of SEGS-2 and their interaction on ACMV-A viral titers (copy number/nanogram of total DNA). Treatment means were compared using least-squares means.

Analysis of SEGS-2 RNA. For transcript analysis, total RNA was isolated from CMB-infected and mock-inoculated leaves at $35 \mathrm{dpi}$ using the mirVana miRNA isolation kit (Ambion). Total RNA (10 $\mu \mathrm{g})$ was subjected to DNase I digestion using a DNA-free kit (Ambion), and DNase-treated RNA ( $1 \mu \mathrm{g}$ ) was used for first-strand cDNA synthesis by Moloney-murine leukemia virus (M-MuLV) reverse transcriptase (200 $\mathrm{U}$ for $1 \mathrm{~h}$ at $42^{\circ} \mathrm{C}$ ). The transcript was amplified using the primer pair 2-hp1F/2-2BR. PCR was for 37 cycles $\left(1 \mathrm{~min}\right.$ at $95^{\circ} \mathrm{C}, 1 \mathrm{~min}$ at $49^{\circ} \mathrm{C}, 1 \mathrm{~min}$ at $72^{\circ} \mathrm{C}$ ). The product ( $825 \mathrm{bp}$ ) was resolved on $1 \%$ (wt/vol) agarose gels, stained with ethidium bromide for UV light visualization, and sequenced.

The $5^{\prime}$ end of the transcript was determined using RACE (64). Total RNA ( $1 \mu \mathrm{g}$ ) from healthy Arabidopsis leaves was heated to $75^{\circ} \mathrm{C}$ for $5 \mathrm{~min}$, followed by reverse transcription with M-MuLV reverse transcriptase (200 $\mathrm{U}$ for $1 \mathrm{~h}$ at $42^{\circ} \mathrm{C}$ ) with a left or right gene-specific primer (LGSP1 or RGSP1; Table S1). The cDNA synthesis product was purified using a QIAquick PCR purification kit (Qiagen) and used in a $\mathrm{dA}$-tailing reaction with terminal transferase $\left(120 \mathrm{U}\right.$ for $1.5 \mathrm{~h}$ at $\left.37^{\circ} \mathrm{C}\right)$. Amplification of the target cDNA was performed using a second set of left (LGSP2) or right (RGSP2) gene-specific primers with Adaptor (dT) 17 that binds to the poly $(A)^{+}$tract added in the dA-tailing reaction and the Adaptor primer that binds to the $5^{\prime}$ end of the Adaptor(dT)17. PCR was performed for RGSP2 for 1 cycle $\left(5 \mathrm{~min}\right.$ at $94^{\circ} \mathrm{C}, 5 \mathrm{~min}$ at $54^{\circ} \mathrm{C}, 40 \mathrm{~min}$ at $72^{\circ} \mathrm{C}$ ) followed by 30 cycles $\left(40 \mathrm{~s}\right.$ at $94^{\circ} \mathrm{C}, 1 \mathrm{~min}$ at $54^{\circ} \mathrm{C}, 3 \mathrm{~min}$ at $72^{\circ} \mathrm{C}$ ) and a final cycle $\left(40 \mathrm{~s}\right.$ at $94^{\circ} \mathrm{C}, 1 \mathrm{~min}$ at $54^{\circ} \mathrm{C}, 15 \mathrm{~min}$ at $72^{\circ} \mathrm{C}$ ). PCR cycle conditions for LGSP2 were similar, except the annealing temperature was $52^{\circ} \mathrm{C}$. The PCR products for primer pairs RGSP2 (257 bp) and LGSP2 (546 bp) were gel purified using a QIAquick gel extraction kit (Qiagen) and sequenced using the RGSP2 or LGSP2 primer, respectively.

Analysis of SEGS-2 episomes in Arabidopsis thaliana. Total DNA was isolated from $1 \mathrm{mg}$ of pooled A. thaliana leaf 3 tissue collected from three plants for each treatment. Virion samples were generated by homogenizing tissue collected from 3 infected leaves $(1 \mathrm{mg})$ in $50 \mathrm{mM}$ Tris, $10 \mathrm{mM} \mathrm{MgSO}, 0.1 \mathrm{M}$ $\mathrm{NaCl}, \mathrm{pH} 7.5$, followed by low-speed centrifugation. The supernatant was subjected to $0.22-\mu \mathrm{m}$ filtration 
followed by DNase I digestion ( $2.5 \mathrm{U}$ for $3 \mathrm{~h}$ at $37^{\circ} \mathrm{C}$ ). Virion DNA was isolated using QIAamp MinElute virus spin kit (Qiagen).

Total and virion DNA were amplified by rolling circle amplification (RCA) using the TempliPhi100 DNA amplification kit (GE Healthcare) according to the manufacturer's instructions. The RCA product was diluted 10 -fold with DNase-free water, and $1 \mu \mathrm{l}$ was used as the template in a 50- $\mu$ I PCR containing the primer pair S2-4F and S2-6R (310 bp; Table S1), using previously established conditions (38). The RCA products were tested for Arabidopsis thaliana genomic DNA contamination using the primer pair PCNA2-F/PCNA2-R according to reference 38.

To determine if the SEGS-2 episomes were single- or double-stranded DNA, total or virion DNA was treated with $1 \mathrm{U}$ of mung bean nuclease (NEB). The digestion products were analyzed for SEGS-2 episomes as described above.

Luciferase and replication assays. SEGS-2 promoter assays in N. tabacum NT-1 cell protoplasts were performed according to published protocols (65). The luciferase reporter cassettes (10 $\mu \mathrm{g}$ DNA/ $2.8 \times 10^{6}$ cells) corresponded to the empty vector (no promoter, negative control), the enhanced $35 \mathrm{~S}$ promoter (positive control) (65), and the P:S2-F and P:S2-R cassettes. The protoplasts were cultured for $36 \mathrm{~h}$ after transfection, resuspended in $250 \mu \mathrm{l}$ of extraction buffer $\left(100 \mathrm{mM} \mathrm{KH}{ }_{2} \mathrm{PO}_{4}, 1 \mathrm{mM}\right.$ EDTA, $10 \mathrm{mM}$ dithiothreitol, $8 \mathrm{mM}$ phenylmethylsulfonyl fluoride, $0.5 \%$ glycerol, $\mathrm{pH} 7.8$ ), sonicated, and centrifuged. Luciferase activity was measured in the resulting supernatants as previously described (65). The assays were repeated four times, and a two-tailed Student's $t$ test was used to compare mean luc activities.

For SEGS-2 replication assays, NT1 protoplasts were electroporated with SEGS-2 plasmids (10 $\mu \mathrm{g} /$ $2.8 \times 10^{6}$ cells $)$ in the presence or absence of an ACMV DNA-A replicon $\left(1.5 \mu \mathrm{g} / 2.8 \times 10^{6}\right.$ cells $)$ and cultured as described previously (66). Total DNA was purified $48 \mathrm{~h}$ posttransfection, and $30 \mu \mathrm{g}$ was digested with Dpnl. Episomal forms of SEGS-2 were analyzed using divergent primer pair 2-4F/2-6R as described above.

In situ hybridization and immunohistochemical staining. Leaves 5 and 6 relative to the center of the rosette were harvested at 35 or $36 \mathrm{dpi}$ from S2-1.0F or Pla-1 plants, respectively, fixed using paraformaldehyde, and embedded in $5 \%$ low-melting-point agarose in $1 \times$ phosphate-buffered saline (PBS) as described previously (67). The leaf tissue was cut into $100-\mu \mathrm{m}$ sections using a Leica VT1000S vibratome (Leica Microsystems).

For in situ hybridization, a digoxigenin-labeled probe corresponding to $415 \mathrm{bp}$ of the ACMV AC1 gene was generated using a PCR DIG probe synthesis kit (Roche Diagnostics) and the primer pair ACMV $400 \mathrm{~F}$ and ACMV 400R (Table S1). PCR was performed in a 50- $\mu$ l reaction mix containing $10 \mathrm{ng}$ of ACMVA DNA with the primer pair described above (Table S1) according to the manufacturer's instructions. Labeled and unlabeled PCR products were analyzed on 1\% agarose gels to determine labeling success. Before use, the probe was denatured at $100^{\circ} \mathrm{C}$ for $5 \mathrm{~min}$ and cooled on ice for $5 \mathrm{~min}$.

Immunohistochemistry used a rabbit antiserum against CaLCuV Rep, a biotinylated anti-rabbit IgG secondary antibody, and horseradish peroxidase conjugated to streptavidin. Preparation procedures, the source of the antibodies, and immunohistochemistry protocol were described previously $(45,68)$.

\section{SUPPLEMENTAL MATERIAL}

Supplemental material is available online only.

SUPPLEMENTAL FILE 1, XLSX file, 0.01 MB.

\section{ACKNOWLEDGMENTS}

We thank Wei Shen for his help in manuscript review and Vincent Fondong for the ACMV clones.

This work was supported by the Bill and Melinda Gates Foundation (OPP1149990) to L.H.-B., J.T.A.-I., and J.N. Under the grant conditions of the Foundation, a Creative Commons Attribution 4.0 Generic License has already been assigned to the authoraccepted manuscript version that might arise from this submission. C.D.A. was supported by an NSF Graduate Research Fellowship and an NCSU Provost Fellowship. L.D.L. was supported by a Fulbright Fellowship.

\section{REFERENCES}

1. Legg JP, Lava Kumar P, Makeshkumar T, Tripathi L, Ferguson M, Kanju E, Ntawuruhunga P, Cuellar W. 2015. Cassava virus diseases: biology, epidemiology, and management. Adv Virus Res 91:85-142. https://doi.org/10 $.1016 /$ bs.aivir.2014.10.001.

2. FAO. 2010. Cassava diseases in central, eastern and southern Africa (CaCESA). FAO, Rome, Italy.

3. FAO. 2014. FAO statistical yearbook 2014 Africa food and agriculture. $\mathrm{FAO}$, Rome, Italy.

4. Karthikeyan C, Patil BL, Borah BK, Resmi TR, Turco S, Pooggin MM, Hohn T, Veluthambi K. 2016. Emergence of a latent Indian cassava mosaic virus from cassava which recovered from infection by a non-persistent Sri
Lankan cassava mosaic virus. Viruses 8:264. https://doi.org/10.3390/ v8100264.

5. Siriwan W, Jimenez J, Hemniam N, Saokham K, Lopez-Alvarez D, Leiva AM, Martinez A, Mwanzia L, Becerra Lopez-Lavalle LA, Cuellar WJ. 2020. Surveillance and diagnostics of the emergent Sri Lankan cassava mosaic virus (Fam. Geminiviridae) in Southeast Asia. Virus Res 285:197959. https://doi .org/10.1016/j.virusres.2020.197959.

6. Wang D, Yao XM, Huang GX, Shi T, Wang GF, Ye J. 2019. First report of Sri Lankan cassava mosaic virus infected cassava in China. Plant Dis 103: 1437. https://doi.org/10.1094/PDIS-09-18-1590-PDN.

7. ICTV. 2019. Virus taxonomy: 2019 release. ICTV, Berlin, Germany. 
8. Stanley J, Gay MR. 1983. Nucleotide sequence of of cassava latent virus DNA. Nature 301:260-2662. https://doi.org/10.1038/301260a0.

9. Rojas MR, Hagen C, Lucas WJ, Gilbertson RL. 2005. Exploiting chinks in the plant's armor: evolution and emergence of geminiviruses. Annu Rev Phytopathol 43:361-394. https://doi.org/10.1146/annurev.phyto.43.040204 .135939.

10. Hanley-Bowdoin L, Settlage SB, Orozco BM, Nagar S, Robertson D. 2000. Geminiviruses: models for plant DNA replication, transcription, and cell cycle regulation. Crit Rev Biochem Mol Biol 35:105-140.

11. Zerbini FM, Briddon RW, Idris A, Martin DP, Moriones E, Navas-Castillo J, Rivera-Bustamante R, Roumagnac P, Varsani A, ICTV Report Committee. 2017. ICTV virus taxonomy profile: Geminiviridae. J Gen Virol 98:131-133. https://doi.org/10.1099/jgv.0.000738.

12. Briddon RW, Patil BL, Bagewadi B, Nawaz-Ul-Rehman MS, Fauquet CM. 2010. Distinct evolutionary histories of the DNA-A and DNA-B components of bipartite begomoviruses. BMC Evol Biol 10:97. https://doi.org/10 .1186/1471-2148-10-97.

13. Hanley-Bowdoin L, Bejarano ER, Robertson D, Mansoor S. 2013. Geminiviruses: masters at redirecting and reprogramming plant processes. Nat Rev Microbiol 11:777-788. https://doi.org/10.1038/nrmicro3117.

14. Mugerwa $H$, Rey MEC, Alicai T, Ateka E, Atuncha H, Ndunguru J, Sseruwagi P. 2012. Genetic diversity and geographic distribution of Bemisia tabaci (Gennadius) (Hemiptera: Aleyrodidae) genotypes associated with cassava in East Africa. Ecol Evol 2:2749-2762. https://doi.org/10.1002/ece3.379.

15. FAOSTAT. 2016. FAO statistical databases. Food and Agriculture Organization (FAO) of the United Nations, Rome, Italy. http://faostatfaoorg/.

16. Duffy S, Holmes EC. 2009. Validation of high rates of nucleotide substitution in geminiviruses: phylogenetic evidence from East African cassava mosaic viruses. J Gen Virol 90:1539-1547. https://doi.org/10.1099/vir.0 .009266-0.

17. Pita JS, Fondong VN, Sangaré A, Otim-Nape GW, Ogwal S, Fauquet CM. 2001. Recombination, pseudorecombination and synergism of geminiviruses are determinant keys to the epidemic of severe cassava mosaic disease in Uganda. J Gen Virol 82:655-665. https://doi.org/10.1099/0022 -1317-82-3-655.

18. Zhou X, Liu Y, Calvert L, Munoz C, Otim-Nape GW, Robinson DJ, Harrison BD. 1997. Evidence that DNA-A of a geminivirus associated with severe cassava mosaic disease in Uganda has arisen by interspecific recombination. J Gen Virol 78:2101-2111. https://doi.org/10.1099/0022-1317-78-8 $-2101$.

19. Sanjuán R, Nebot MR, Chirico N, Mansky LM, Belshaw R. 2010. Viral mutation rates. J Virol 84:9733-9748. https://doi.org/10.1128/JVI.00694-10.

20. Lefeuvre $P$, Moriones E. 2015. Recombination as a motor of host switches and virus emergence: geminiviruses as case studies. Curr Opin Virol 10: 14-19. https://doi.org/10.1016/j.coviro.2014.12.005.

21. Fondong VN, Pita JS, Rey ME, de Kochko A, Beachy RN, Fauquet CM. 2000. Evidence of synergism between African cassava mosaic virus and a new double-recombinant geminivirus infecting cassava in Cameroon. J Gen Virol 81:287-297. https://doi.org/10.1099/0022-1317-81-1-287.

22. Deng D, Otim-Nape WG, Sangare A, Ogwal S, Beachy RN, Fauquet CM. 1997. Presence of a new virus closely related to East African cassava mosaic geminivirus, associated with cassava mosaic outbreak in Uganda. African J Root Tuber Crops 2:23-28.

23. Rabbi IY, Hamblin MT, Kumar PL, Gedil MA, Ikpan AS, Jannink J-L, Kulakow PA. 2014. High-resolution mapping of resistance to cassava mosaic geminiviruses in cassava using genotyping-by-sequencing and its implications for breeding. Virus Res 186:87-96. https://doi.org/10.1016/j.virusres.2013 .12.028.

24. Akano O, Dixon O, Mba C, Barrera E, Fregene M. 2002. Genetic mapping of a dominant gene conferring resistance to cassava mosaic disease. Theor Appl Genet 105:521-525. https://doi.org/10.1007/s00122-002-0891-7.

25. Briddon RW, Bull SE, Amin I, Idris AM, Mansoor S, Bedford ID, Dhawan P, Rishi N, Siwatch SS, Abdel-Salam AM, Brown JK, Zafar Y, Markham PG. 2003. Diversity of DNA $\beta$, a satellite molecule associated with some monopartite begomoviruses. Virology 312:106-121. https://doi.org/10 .1016/s0042-6822(03)00200-9.

26. Mansoor S, Briddon RW, Zafar Y, Stanley J. 2003. Geminivirus disease complexes: an emerging threat. Trends Plant Sci 8:128-134. https://doi.org/10 .1016/S1360-1385(03)00007-4.

27. Briddon RW, Martin DP, Roumagnac $P$, Navas-Castillo J, Fiallo-Olivé E, Moriones E, Lett J-M, Zerbini FM, Varsani A. 2018. Alphasatellitidae: a new family with two subfamilies for the classification of geminivirus- and nanovirus-associated alphasatellites. Arch Virol 163:2587-2600. https:// doi.org/10.1007/s00705-018-3854-2.
28. Nawaz-UI-Rehman MS, Fauquet CM. 2009. Evolution of geminiviruses and their satellites. FEBS Lett 583:1825-1832. https://doi.org/10.1016/j.febslet .2009.05.045.

29. Zhou X. 2013. Advances in understanding begomovirus satellites. Annu Rev Phytopathol 51:357-381. https://doi.org/10.1146/annurev-phyto-082712102234.

30. Hassan I, Orílio AF, Fiallo-Olivé E, Briddon RW, Navas-Castillo J. 2016. Infectivity, effects on helper viruses and whitefly transmission of the deltasatellites associated with sweepoviruses (genus Begomovirus, family Geminiviridae). Sci Rep 6:30204. https://doi.org/10.1038/srep30204.

31. Rosario K, Marr C, Varsani A, Kraberger S, Stainton D, Moriones E, Polston JE, Breitbart M. 2016. Begomovirus-associated satellite DNA diversity captured through vector-enabled metagenomic (VEM) surveys using whiteflies (Aleyrodidae). Viruses 8:36. https://doi.org/10.3390/v8020036.

32. Gnanasekaran P, KishoreKumar R, Bhattacharyya D, Vinoth Kumar R, Chakraborty S. 2019. Multifaceted role of geminivirus associated betasatellite in pathogenesis. Mol Plant Pathol 20:1019-1033. https://doi.org/10 $.1111 / \mathrm{mpp} .12800$.

33. Yang X, Guo W, Li F, Sunter G, Zhou X. 2019. Geminivirus-associated betasatellites: exploiting chinks in the antiviral arsenal of plants. Trends Plant Sci 24:519-529. https://doi.org/10.1016/j.tplants.2019.03.010.

34. Idris AM, Shahid MS, Briddon RW, Khan AJ, Zhu JK, Brown JK. 2011. An unusual alphasatellite associated with monopartite begomoviruses attenuates symptoms and reduces betasatellite accumulation. J Gen Virol 92: 706-717. https://doi.org/10.1099/vir.0.025288-0.

35. Mar TB, Mendes IR, Lau D, Fiallo-Olivé E, Navas-Castillo J, Alves MS, Murilo Zerbini F. 2017. Interaction between the New World begomovirus Euphorbia yellow mosaic virus and its associated alphasatellite: effects on infection and transmission by the whitefly Bemisia tabaci. J Gen Virol 98: 1552-1562. https://doi.org/10.1099/jgv.0.000814.

36. Harimalala M, De Bruyn A, Hoareau M, Andrianjaka A, Ranomenjanahary S, Reynaud B, Lefeuvre P, Lett JM. 2013. Molecular characterization of a new alphasatellite associated with a cassava mosaic geminivirus in Madagascar. Arch Virol 158:1829-1832. https://doi.org/10.1007/s00705-013 -1664-0.

37. Patil BL, Fauquet CM. 2010. Differential interaction between cassava mosaic geminiviruses and geminivirus satellites. J Gen Virol 91:1871-1882. https:// doi.org/10.1099/vir.0.019513-0.

38. Ndunguru J, De Leon L, Doyle CD, Sseruwagi P, Plata G, Legg JP, Thompson G, Tohme J, Aveling T, Ascencio-lbanez JT, Hanley-Bowdoin L. 2016. Two novel DNAs that enhance symptoms and overcome CMD2 resistance to cassava mosaic disease. J Virol 90:4160-4173. https://doi.org/ 10.1128/JVI.02834-15.

39. Pierce EJ, Rey MEC. 2013. Assessing global transcriptome changes in response to South African cassava mosaic virus [ZA-99] infection in susceptible Arabidopsis thaliana. PLoS One 8:e67534. https://doi.org/10 .1371/journal.pone.0067534.

40. Lee S, Stenger DC, Bisaro DM, Davis KR. 1994. Identification of loci in Arabidopsis that confer resistance to geminivirus infection. Plant J 6:525-535 . https://doi.org/10.1046/j.1365-313x.1994.6040525.x.

41. Stenger DC, Revington GN, Stevenson MC, Bisaro DM. 1991. Replicational release of geminivirus genomes from tandemly repeated copies: evidence for rolling-circle replication of a plant viral DNA. Proc Natl Acad Sci U S A 88:8029-8033. https://doi.org/10.1073/pnas.88.18.8029.

42. Reyes MI, Flores-Vergara MA, Guerra-Peraza O, Rajabu C, Desai J, Hiromoto-Ruiz YH, Ndunguru J, Hanley-Bowdoin L, Kjemtrup S, AscencioIbáñez JT, Robertson D. 2017. A VIGS screen identifies immunity in the Arabidopsis Pla-1 accession to viruses in two different genera of the Geminiviridae. Plant J 92:796-807. https://doi.org/10.1111/tpj.13716.

43. Briddon RW, Stanley J. 2006. Subviral agents associated with plant singlestranded DNA viruses. Virology 344:198-210. https://doi.org/10.1016/j .virol.2005.09.042.

44. Sivalingam PN, Varma A. 2012. Role of betasatellite in the pathogenesis of a bipartite begomovirus affecting tomato in India. Arch Virol 157: 1081-1092. https://doi.org/10.1007/s00705-012-1261-7.

45. Ascencio-lbáñez JT, Sozzani R, Lee T-J, Chu T-M, Wolfinger RD, Cella R, Hanley-Bowdoin L. 2008. Global analysis of Arabidopsis gene expression uncovers a complex array of changes impacting pathogen response and cell cycle during geminivirus infection. Plant Physiol 148:436-454. https:// doi.org/10.1104/pp.108.121038.

46. Hesketh EL, Saunders K, Fisher C, Potze J, Stanley J, Lomonossoff GP, Ranson NA. 2018. The $3.3 \AA$ structure of a plant geminivirus using cryoEM. Nat Commun 9:2369. https://doi.org/10.1038/s41467-018-04793-6. 
47. Saunders K, Richardson J, Lawson DM, Lomonossoff GP. 2020. Requirements for the packaging of geminivirus circular single-stranded DNA: effect of DNA length and coat protein sequence. Viruses 12:1235. https:// doi.org/10.3390/v12111235.

48. Jeske $H$, Lütgemeier $M$, Preiss W. 2001. DNA forms indicate rolling circle and recombination-dependent replication of Abutilon mosaic virus. EMBO J 20:6158-6167. https://doi.org/10.1093/emboj/20.21.6158.

49. Xu X, Qian Y, Wang Y, Li Z, Zhou X. 2019. Iterons homologous to helper geminiviruses are essential for efficient replication of betasatellites. J Virol 93:e01532-18. https://doi.org/10.1128/JVI.01532-18.

50. Catoni M, Noris E, Vaira AM, Jonesman T, Matić S, Soleimani R, Behjatnia SAA, Vinals N, Paszkowski J, Accotto GP. 2018. Virus-mediated export of chromosomal DNA in plants. Nat Commun 9:5308. https://doi.org/10 .1038/s41467-018-07775-w.

51. Cheong YH, Chang H-S, Gupta R, Wang X, Zhu T, Luan S. 2002. Transcriptional profiling reveals novel interactions between wounding, pathogen, abiotic stress, and hormonal responses in Arabidopsis. Plant Physiol 129: 661-677. https://doi.org/10.1104/pp.002857.

52. Marhava P, Hoermayer L, Yoshida S, Marhavý P, Benková E, Friml J. 2019. Re-activation of stem cell pathways for pattern restoration in plant wound healing. Cell 177:957-969. https://doi.org/10.1016/j.cell.2019.04 .015 .

53. Colicchio J, Kelly J, Hileman L. 2020. Mimulus sRNAs are wound responsive and associated with transgenerationally plastic genes but rarely both. Int J Mol Sci 21:7552. https://doi.org/10.3390/ijms21207552.

54. Arguello-Astorga G, Ascencio-lbanez JT, Dallas MB, Orozco BM, HanleyBowdoin L. 2007. High-frequency reversion of geminivirus replication protein mutants during infection. J Virol 81:11005-11015. https://doi.org/ 10.1128/JVI.00925-07.

55. Kong LJ, Orozco BM, Roe JL, Nagar S, Ou S, Feiler HS, Durfee T, Miller AB, Gruissem W, Robertson D, Hanley-Bowdoin L. 2000. A geminivirus replication protein interacts with the retinoblastoma protein through a novel domain to determine symptoms and tissue specificity of infection in plants. EMBO J 19:3485-3495. https://doi.org/10.1093/emboj/19.13.3485.

56. Zhang T, Wu A, Yue Y, Zhao Y. 2020. uORFs: important cis-regulatory elements in plants. Int J Mol Sci 21:6238. https://doi.org/10.3390/ ijms21176238.

57. Shaw CH. 1995. Introduction of cloning plasmids into Agrobacterium tumefaciens, p 33-37. In Jones $\mathrm{H}$ (ed), Plant gene transfer and expression protocols. Springer New York, Totowa, NJ.
58. Mara C, Grigorova B, Liu Z. 2010. Floral-dip transformation of Arabidopsis thaliana to examine pTSO2:: $\beta$-glucuronidase reporter gene expression. J Vis Exp 40:1952. https://doi.org/10.3791/1952.

59. Hoyer JS, Fondong VN, Dallas MM, Aimone CD, Deppong DO, Duffy S, Hanley-Bowdoin L. 2020. Deeply sequenced infectious clones of key cassava begomovirus isolates from Cameroon. Microbiol Resour Announc 9: e00802-20. https://doi.org/10.1128/MRA.00802-20.

60. Abouzid AM, Hiebert E, Strandberg JO. 1992. Cloning, identification and partial sequencing of the genomic components of a geminivirus infecting the Brassicaceae. Phytopathology 82:1070.

61. Doyle JJDJ. 1990. Isolation of plant DNA from fresh tissue. Focus 12:13-15.

62. Rajabu CA, Kennedy GG, Ndunguru J, Ateka EM, Tairo F, Hanley-Bowdoin L, Ascencio-lbáñez JT. 2018. Lanai: a small, fast growing tomato variety is an excellent model system for studying geminiviruses. J Virol Methods 256:89-99. https://doi.org/10.1016/j.jviromet.2018.03.002.

63. Aimone CD, Hoyer JS, Dye AE, Deppong DO, Duffy S, Carbone I, HanleyBowdoin L. 2020. An improved experimental pipeline for preparing circular ssDNA viruses for next-generation sequencing. bioRxiv https://doi .org/10.1101/2020.09.30.321224:2020.2009.2030.321224.

64. Yeku O, Frohman MA. 2011. Rapid amplification of cDNA ends (RACE), p 107-122. In Nielsen H (ed), RNA: methods and protocols. Humana Press, Totowa, NJ.

65. Eagle PA, Orozco BM, Hanley-Bowdoin L. 1994. A DNA sequence required for geminivirus replication also mediates transcriptional regulation. Plant Cell 6:1157-1170. https://doi.org/10.1105/tpc.6.8.1157.

66. Fontes EP, Eagle PA, Sipe PS, Luckow VA, Hanley-Bowdoin L. 1994. Interaction between a geminivirus replication protein and origin DNA is essential for viral replication. J Biol Chem 269:8459-8465. https://doi.org/10 .1016/S0021-9258(17)37216-2.

67. Shen W, Hanley-Bowdoin L. 2006. Geminivirus infection up-regulates the expression of two Arabidopsis protein kinases related to yeast SNF1- and mammalian AMPK-activating kinases. Plant Physiol 142:1642-1655. https://doi.org/10.1104/pp.106.088476.

68. Shen W, Dallas MB, Goshe MB, Hanley-Bowdoin L. 2014. SnRK1 phosphorylation of AL2 delays cabbage leaf curl virus infection in Arabidopsis. J Virol 88:10598-10612. https://doi.org/10.1128/JVI.00761-14.

69. Casson SA, Chilley PM, Topping JF, Evans IM, Souter MA, Lindsey K. 2002. The POLARIS gene of Arabidopsis encodes a predicted peptide required for correct root growth and leaf vascular patterning. Plant Cell 14: 1705-1721. https://doi.org/10.1105/tpc.002618. 